BNL-112703-2015-IR

\title{
Performance Evaluation of Mineral Additive-free Perfluoropolymer Nanocomposite O-ring in Simulated Geothermal Environments of 300C
}

\author{
Toshifumi Sugama, Tatiana Pyatina
}

December 2015

\author{
Sustainable Energy Technologies Department \\ Brookhaven National Laboratory
}

\author{
U.S. Department of Energy \\ USDOE Office of Energy \\ Efficiency and Renewable Energy (EERE), \\ Geothermal Technologies Office (EE-4G)
}




\section{DISCLAIMER}

This report was prepared as an account of work sponsored by an agency of the United States Government. Neither the United States Government nor any agency thereof, nor any of their employees, nor any of their contractors, subcontractors, or their employees, makes any warranty, express or implied, or assumes any legal liability or responsibility for the accuracy, completeness, or any third party's use or the results of such use of any information, apparatus, product, or process disclosed, or represents that its use would not infringe privately owned rights. Reference herein to any specific commercial product, process, or service by trade name, trademark, manufacturer, or otherwise, does not necessarily constitute or imply its endorsement, recommendation, or favoring by the United States Government or any agency thereof or its contractors or subcontractors. The views and opinions of authors expressed herein do not necessarily state or reflect those of the United States Government or any agency thereof. 
Performance Evaluation of Mineral Additive-free Perfluoropolymer Nanocomposite Oring in Simulated Geothermal Environments at $300^{\circ} \mathrm{C}$

\author{
Prepared for \\ The U.S. Department of Energy \\ Energy Efficiency and Renewable Energy \\ Geothermal Technologies Program \\ 1000 Independence Avenue SW \\ Washington, D.C. 20585
}

\author{
Prepared by \\ Toshifumi Sugama and Tatiana Pyatina \\ Sustainable Energy Technologies Department \\ Brookhaven National Laboratory \\ Upton, NY 11973-5000
}

December 2015

Notice: This manuscript has been authored by an employee of Brookhaven Science Associates, LLC under Contract No. DE-SC0012704 with the U.S. Department of Energy. The publisher by accepting the manuscript for publication acknowledges that the United States Government retains a non-exclusive, paid-up, irrevocable, world-wide license to publish or reproduce the published form of this manuscript, or allow others to do so, for the United States Government purposes. 


\begin{abstract}
The objective of this research was to evaluate the performance of O-rings made with a mineral additive-free perfluoropolymer (FFKM) nanocomposite in mitigating irremovable silica- and silicate-scaling, inhibiting oxidative reactions, minimizing the changes in mechanical behaviors, and maintaining the integrity of O-rings after their exposure to the five different simulated geothermal environments at $300^{\circ} \mathrm{C}$ : 1$) 0.01 \mathrm{~N}$ sodium metasilicate (SMS)-laden non-aerated $\left(\mathrm{N}_{2}\right.$ (g) saturated) steam-cooling cycles; 2) 0.01N SMS-laden aerated steam-cooling cycles; 3) waterbased drilling fluid; 4) $\mathrm{CO}_{2}$-rich geo-brine fluid; and, 5) heat-cool water quenching cycles (thermal shock). All the thermochemical environments 1 to 4 were carried out under a pressure of 8.3 MPs. For comparison, various mineral additive-filled EPDM, FEPM, and FFKM composite O-rings were employed. One major characteristic of the mineral-free nanocomposite O-ring was the fact that its tensile strength and ultimate elongation were equal to, and even higher than those of the mineral additive-filled composite O-rings.
\end{abstract}

The magnitude of silica- and silicate-scaling on O-ring surfaces was governed by three major factors: 1) The susceptibility of the $-\mathrm{CH}_{2}$ - groups in a polymer to oxidative reactions; 2) the incorporation of oxidation derivatives, such as $\mathrm{C}=\mathrm{C}, \mathrm{C}=\mathrm{O}$, and $\mathrm{COO}^{-}$groups, into the polymer; and, 3) water uptake by the mineral additive and the degraded polymer. Among these environments, the geo-brine fluid was most hostile one in fostering the precipitation of these scales, corresponding to the dissipation and disappearance of $-\mathrm{CH}_{2}$ - groups by oxidation, the greater incorporation of oxidation derivatives, and increased water uptake. The water uptake by O-rings under pressure was one of the critical factors in evaluating O-ring's integrity because of the loss in the effectiveness of sealing. Such water uptake was not only due to the oxidative degradation of O-rings, but also was associated with the kind of mineral additives. For instance, although the FFKM matrix in a composite had great resistance to oxidation, the $\mathrm{K}_{2} \mathrm{O}$-related mineral additive in the composite absorbed a large amount of water as high as $13.8 \%$, compared with a $6.4 \%$ of CaO-related mineral in the FEPM composite. In contrast, mineral-free FFKM nanocomposite and mineral-filled EPDM did not absorb any water in all thermochemical environments responsible for lower susceptibility of $-\mathrm{CH}_{2}$ - groups, the minimized rate of oxidation, and the limited scaling. On the other hand, the high rate of scale deposition played pivotal rules in changing the mechanical behaviors of the O-rings; namely, the elastic properties of O-rings were enhanced as means of their degradation. Such degradation engendered an extended softening of the O-rings, corresponding to their reduced tensile strength and their increased ultimate elongation.

In the thermal shock environment, one inevitable factor promoting the degradation of the O-ring was the sensitivity of the mineral additive to the reaction with $\mathrm{CO}_{2}$ (gas) in terms of carbonation. In fact, the $\mathrm{K}_{2} \mathrm{O}$-related additive-filled FFKM was detrimental to this environment; namely, the disintegration of this O-ring was dependent on the in-situ transformation of $\mathrm{K}_{2} \mathrm{O}$ additive into water-soluble K carbonate, but not was independent of the oxidation of FFKM itself. Meanwhile, 
EPDM underwent very high oxidation, and this O-ring was disintegrated, allowing water to permeate through it.

Nevertheless, the mineral additive-free FFKM nanocomposite displayed the best performance in maintaining the integrity of O-ring in all these environments, so demonstrating that it has a high potential for not only use as O-rings, but also as the other components of drilling such as gaskets, seals, and packers.

\section{Introduction}

Geothermal-heat energy fields including the hot water-tapping down-borehole hydrothermal reservoirs, and the reservoirs created by the combination of hydro-fracture network and hydrostimulate on in impervious hot rock, called Enhanced Geothermal Systems (EGSs), are very harsh and challengeable environments for extending the service life-cycle of any material system. Some geothermal wells have down-hole temperatures over $250^{\circ} \mathrm{C}$, together with hostile thermochemical environments containing highly concentrated corrosive $\mathrm{CO}_{2}$ (g) ${ }^{-}$and $\mathrm{H}_{2} \mathrm{~S}_{(\mathrm{g})}{ }^{-}$ induced acids. The components of drilling tools, such as O-rings, gaskets, seals, and packers, are exposed not only to a chemical mix containing these corrosive gasses in the down-hole reservoir, but also to water-based drilling fluids, including some organic compounds [1]. Furthermore, the hypersaline geothermal brine imposes two inevitable concerns in maintaining the tools' components: One is accelerating the corrosion of metal substrates; the other is the deposition of silica-and silicate-related scales on solid receptive surfaces. For the latter, as is well documented [2-4], the source of these scales is dissolved silica as the chemical state of monomeric silicic acid, $\mathrm{Si}(\mathrm{OH})_{4}$, in geo-brine fluid at high temperatures. The silicic acid possesses two different chemical activities to generate the scales: One is the formation of polymeric silicic acid, $\left[\mathrm{SiO}_{\mathrm{x}}(\mathrm{OH})_{4-2 \mathrm{x}}\right]_{\mathrm{n}}$ along with $\mathrm{Si}-\mathrm{O}-\mathrm{Si}$ linkages by self-condensation reactions between the silanol groups on two monomeric silicic acids, eventually leading to the creation of silica minerals and/or colloidal silica particles as scales when they reach solid receptive surfaces; the other is the reactions with $\mathrm{Ca}, \mathrm{Mg}, \mathrm{Al}, \mathrm{Fe}, \mathrm{Zn}$, etc. in brine to form silicate scales. Also, the silicic acid would react with alkali metals like $\mathrm{Na}$ and $\mathrm{K}$ in brine to $\mathrm{Na}$ and $\mathrm{K}$ silicates, but these silicates are soluble in water. The precipitation of silica scales seems to occur preferentially at locations of well boreholes where the temperature of geo-brine fluid is decreased [5]. Nevertheless, once the receptive surface is covered with these scales, extra layers of scales accumulate on these newly formed scale layers. In EGSs, when an elastomer packer is applied to flow diverting material in isolated fracturing and stimulating zones, one concern is the possibility of packer's directly touching hot rock, and following this by its contact with the cool fracturing fluid later on; hence, the packer may be required to possess the resistance to heat-cooling cycles.

Thus, there is no doubt that geothermal fields involve many different harsh environments; hence, it is very important to identify the elastomeric end-products compatible with each different environment at high temperature, and to obtain information on the reliability of the end-products in these environments. Such reliability substantially would reduce downtime costs including strip-down time, repair time, material replacement, and installation in the field, consequently reducing the expense of operating and maintaining wells and power plants. In response to these problems, our previous work [6] focused on investigating and evaluating the stability and 
degradation of the commercial O-rings made with five fluorocarbon- and one hydrocarbon-based elastomeric polymers. The former included poly[vinylidene fluoride (VDF)-cohexafluoropropylene (HFP), type I FKM] copolymer, poly[vinylidene fluoride (VDF)-cohexafluoropropylene (HFP)-co-tetrafluoroethylene (TFE), type II FKM] terpolymer, poly[tetrafluoroethylene (TFE)-co- propylene (P), FEKM] copolymer, poly[tetrafluoroethylene (TFE)-co-perfluoromethylvinylether (PMVE), FFKM] copolymer, and poly[siloxane (PS)-cotrifluoropropylpolysiloxane (TFPPS), FSR] copolymer, and the latter was the ethylene propylene diene monomer (EPDM) polymer, consisting of a poly(ethylene-co-propylene-co-5-ethylidene-2norbornene) a terpolymer structure. These O-rings were exposed to five different simulated geothermal environments at $300^{\circ} \mathrm{C}$ : 1) Drilling fluid, 2) $\mathrm{CO}_{2}$-rich reservoir brine fluid, 3) aerated steam-cooling cycles, 4) non-aerated steam-cooling cycles, and, 5) heating in air-water quenching thermal shock.

This test results suggested that the reliability of the O-rings depended on the elastomer chemistry and the exposure environment. Generally, in the test environments, the hydrocarbon bonds underwent oxidation with the formation of $(\mathrm{C}=\mathrm{C})$ - and $\left(\mathrm{COO}^{-}\right)$-containing derivatives. Elastomers with high number of these bonds, such as EPDM and FEPM, were highly sensitive to the environment of heat-quenching thermal-shock tests. However, these elastomers performed reasonably well in chemically aggressive environments, such as drilling- and geo-brine fluids, and showed a relatively lower amount of silica-and silicate-scaling. Elastomers with fluorosubstituted hydrocarbons in their structures, such as hexafluoropropylene (HFP) in type I FKM and HFP, and tetrafluroethylene (TFE) in type II FKM, were much more resistant to thermalshock environment than that of hydrocarbons-rich elastomers. However, the former were more sensitive to the aggressive drilling and geo-brine fluids, where calcium cations from these fluids permeated into the O-rings creating undesirable defects, and impairing their mechanical properties. The FFKM, assembled by fluorocarbon backbone chains and lacking hydrocarbon chains, displayed outstanding compatibility with all the environments. However, its only drawback was the precipitation of silica- and silicate-scales on O-ring surfaces during the exposure in geo-brine fluid and drilling fluid, strongly suggesting that the outermost surface site of the FFKM copolymer might have undergone a physicochemical modification during the exposure to them. Finally, although FSR possessed the highest thermal decomposition temperature as means of great heat stability among these elastomeric polymers, it was extremely susceptible to hydrothermal oxidation; this susceptibility caused severe disintegration of the Oring in all environments, indicating its poor suitability for use in geothermal fields.

Considering the advanced polymerization technology for fluoropolymers, the branching and pseudo-living technology using a fluorinated diene, $\mathrm{CH}_{2}=\mathrm{CH}\left(\mathrm{CF}_{2}\right)_{6} \mathrm{CH}=\mathrm{CH}_{2}$, as co-curing and crosslinking agent, is very attractive for creating additional crosslinked structures in fluoropolymers. Furthermore, this technology allows us to assemble the highly crosslinked nanosized perflouoropolymer particles as organic nano-fillers that can be blended with FFKM to produce the FFKM nanocomposite [7-9]. The major benefit of this nanocomposite is to eliminate the incorporation of any mineral-related filler into FFKM, thereby alleviating two critical concerns about the failing of O-rings: One is the leaching of minerals from composite; the other is the reactions of minerals with the gaseous- and aqueous-reactants present in environments. 
Based upon the information described above, our particular interest was to evaluate and characterize the performance of O-rings made with a mineral-free FFKM nanocomposite in inhibiting silica- and silicate-fouling and oxidation in four silica- and silicate-containing environments at $300^{\circ} \mathrm{C} ; 1$ ) a sodium metasilicate-dissolved steam-cooling cycle in $\mathrm{N}_{2}$ and 2) in air, 3) Ca-bentonite clay (aluminum phyllosilicate)-based drilling fluid, and 4) geo-brine fluid. Additionally, the ability of this nanocomposite O-ring to resist the thermal shock was also investigated. For comparison, the mineral-filled FFKM-, EPDM-, and FEPM-composites were employed and exposed them to the same environments. The obtained data were correlated directly with two important factors governing the reliability of O-rings in these environments; the first factor was the changes in their mechanical behaviors including tensile strength and ultimate elongation, and second one was the efficacy of mineral additives on their mechanical behaviors and thermochemical compatibility, compared with that of a mineral-free O-ring. The physicochemical factors to be assessed and characterized included the following: The exploration of topographical features of O-ring's surface by the coverage with silica- and silicate-fouling, the extent of oxidation, identification of oxidation derivatives, their thermal stability and degradation, their water uptake by degradation, morphological alteration, and changes in their mechanical properties. Obtaining information on these factors was accomplished using ATR-FTIR, TGA, micro-energy dispersive X-ray, and ASTM tensile strength and ultimate elongation testing, and also by visual observations of the changes in the O-ring's appearance.

Integrating all these data obtained from the objectives described above in conjunction with our previous study would lead to the recommendation of some potential elastomeric materials for the field validation tests in future at the geothermal power plant sites in ensuring that screened materials remain satisfactorily.

\section{Experimental procedures}

\subsection{Materials}

Four different elastomeric polymer-based O-ring composites were supplied by Rainier Rubber Corp. Among those were mineral additive-filled-EPDM, -FEPM, and -FFKMs (denoted as FFKM-A) composites, and a mineral-free FFKM nanocomposite marked as FFKM-C. The E. I. du Pont de Nemours and Company provided us with other mineral-filled FFKM composites marked as FFKM-B. Table 1 shows the composition of the major oxides related to the mineral additives present in these O-rings using the micro energy-dispersive $\mathrm{X}$-ray spectrometer ( $\mu$ EDX). $0.01 \mathrm{~N}$ sodium metasilicate (SMS), $\mathrm{Na}_{2} \mathrm{SiO}_{4}$, solution at $\mathrm{pH} 11.8$ was used as the dissolved silica in the stream.

Table 1. Major oxide compounds related to the mineral additives present in various O-rings

\begin{tabular}{lllll}
\hline & $\mathrm{BrO}_{2,}, \%$ & $\mathrm{CaO}, \%$ & $\mathrm{ZnO}, \%$ & $\mathrm{~K}_{2} \mathrm{O}, \%$ \\
\hline EPDM & 0.0 & 54.8 & 45.2 & 0.0 \\
FEPM & 0.0 & 100 & 0.0 & 0.0 \\
FFKM-A & 19.3 & 6.9 & 73.8 & 0.0 \\
FFKM-B & 0.0 & 0.0 & 0.0 & 100 \\
\hline
\end{tabular}




\begin{tabular}{lllll}
\hline FFKM-C & 0.0 & 0.0 & 0.0 & 0.0
\end{tabular}

\subsection{Measurements}

Five different exposure environments were employed in this work: The first environmental condition, denoted as No. 1 , was 5 -cycle $300^{\circ} \mathrm{C}-24 \mathrm{hr} 0.01 \mathrm{~N}$ sodium metasilicate (SMS) nonaerated $\left(\mathrm{N}_{2}\right.$ (g) saturated) steam- $25^{\circ} \mathrm{C}$ cooling; the No. 2 condition was 5 -cycle $300^{\circ} \mathrm{C}-24 \mathrm{hr}$ $0.01 \mathrm{~N}$ SMS aerated steam- $25^{\circ} \mathrm{C}$ cooling; the third, No. 3, was exposure in water-based drilling fluid (pH 9-10) at $300^{\circ} \mathrm{C}$ for 7 days; fourth, No. 4, was exposure in $\mathrm{CO}_{2}$-rich geo-brine fluid (pH 4-5) at $300^{\circ} \mathrm{C}$ for 7 days; and, the fifth, No. 5, was 5-cycle thermal shock (one cycle: $300^{\circ} \mathrm{C}$ air heating for $24 \mathrm{hrs}$, and then $25^{\circ} \mathrm{C}$ deionized (D.I.) water quenching). These thermochemicalexposure tests were carried out under a pressure of $8.3 \mathrm{MPa}$. Details of the first test procedure are as follows: First, $30 \%$ of the total volume of an autoclave was filled with an $0.01 \mathrm{~N}$ SMS solution; second, the O-rings were hung in the head space; third, the autoclave was sealed; fourth, $\mathrm{N}_{2}$ gas was injected in autoclave until all the air present in head space was replaced by $\mathrm{N}_{2}$; fifth, the autoclave was heated to $300^{\circ} \mathrm{C}$, and held at that temperature for 24 hours; and, finally, the autoclave was cooled to room temperature at rate of $50^{\circ} \mathrm{C} /$ hour. This steam-cooling process was repeated 5 times. The same process, except for $\mathrm{N}_{2}$ saturation, was carried out in the conventional $300^{\circ} \mathrm{C} 0.01 \mathrm{~N}$ SMS steam-cooling 5-cycle testing for the No. 2 condition in terms of the aerated steam. All of the O-rings after exposure to all the environments were physically cleaned with a D.I. water-soaked napkin to remove any non-adhering substances and contaminants from their surfaces, and then left at room temperature for 7 days before conducting the post-test analyses. The chemical composition of the drilling fluid and $\mathrm{CO}_{2}$-rich geo-brine fluid employed in this study are given in Tables 2 and 3.

To characterize changes in the mechanical behaviors of the O-rings exposed to different environments, the tensile strength and ultimate elongation of both exposed and non-exposed Orings were determined in accordance with ASTM D1414 using Electromechanical Instron System. Attenuated Total Reflectance-Fourier Transform Infrared Spectroscopy (ATR-FTIR) was used to obtain information on whether irremovable silicate scale was precipitated on the Oring's surfaces, and also to identify the oxidation derivatives that were incorporated into elastomeric polymers-made O-rings exposed to these environments. The studies of thermochemical- and thermal shock-stabilities and the extent of oxidation were carried out by Thermo Gravimetric Analysis (TGA) at the heating rate of $20^{\circ} \mathrm{C} / \mathrm{min}$ in a $\mathrm{N}_{2}$ flow, and then the Derivative Thermogravimetry (DTG) data obtained from TGA was used to gain such information. The micro energy-dispersive X-ray spectrometer ( $\mu \mathrm{EDX}$ ) was employed to conduct topographical mapping analysis and to obtain distribution images of silicate scaling over the Orings, and also to estimate its relative amount. 
Table 2. Composition of the drilling fluid mimic.

\begin{tabular}{ll} 
Major Component & Percent \\
\cline { 2 - 2 } Water & $74-83$ \\
Barite & $10-15$ \\
Ca-Bentonite & $5-7$ \\
Caustic soda & 0.3 \\
Soda ash & 1 \\
Polyanionic cellulose & $0.3-1.2$ \\
Xanthan gum & $0.3-0.5$ \\
Starch & $0.5-1$
\end{tabular}

Table 3. Composition of the $\mathrm{CO}_{2}$-rich brine.

\begin{tabular}{ll} 
Major Components & Percent \\
\cline { 2 - 2 } Chlorine & 13.5 \\
Sodium & 6 \\
Calcium & 2 \\
Potassium & 1.5 \\
Magnesium & 0.9 \\
Minor Components & $\underline{\text { PPM }}$ \\
\hline Carbon dioxide & 15,000 \\
Silicon & 2500 \\
Manganese & 930 \\
Lithium & 410 \\
Zinc & 370 \\
Boron & 330 \\
Barium & 130 \\
Dihydrogen sulfide & 70
\end{tabular}

\section{Results and discussion}

\subsection{Tensile strength and ultimate elongation}

Figure 1 shows the changes in tensile strength of EPDM-, FEPM-, and FFKM-A,-B, and C-based O-rings after exposure in these five different environments. For the control as unexposed sample, all the O-rings with the exception of FFKM-B had a similar tensile strength, ranging from 3.5 to 3.9 MPa. In contrast, the strength of FFKM-B was around one MPa, seemingly suggesting that there are two ways to develop the tensile strength: One was the incorporation of appropriate 
mineral additives into elastomeric polymers; the other was by using a mineral-free nanoelastomeic polymer composite like FFKM-C. For the former, as listed in Table 1, the $\mathrm{K}_{2} \mathrm{O}-$ relaed additive attributed to FFKM-B was not as effective in improving tensile strength as were the $\mathrm{BrO}_{2-}$, $\mathrm{CaO}-$, and $\mathrm{ZnO}$-related minerals. For the latter, the FFKM-C nanocomposite O-ring had equal and even higher tensile strength, compared with that of mineral-filled O-rings. When these O-rings were subjected to No.1 and 2 environments (SMS-laden steam/cooling cycle tests in $\mathrm{N}_{2}$ and air), all the O-rings without FFKM-A revealed the increase of this strength in both $\mathrm{N}_{2}$. and air. Furthermore, the aerated steam engendered a higher increasing rate of strength than that of those in $\mathrm{N}_{2}$. The FFKM-B showed no significant difference between the strengths in $\mathrm{N}_{2}$ and air. A considerable reduction of strength in these steam environments was observed from the FFKM-A, corresponding to 7.8- and 11.3-fold loss in $\mathrm{N}_{2}$ and air, respectively. Thus, no further exposures to drilling fluid and brine were made for this O-ring. The No. 3 and 4 environments (drilling fluid and brine) caused a reduction in strength for all O-rings; the rate of this reduction by brine was markedly higher than that after exposure in drilling fluid. In the No. 5 environment (thermal shock), two O-rings made with EPDM and FFKM-B completely disintegrated. All the other O-rings remained intact, although some reduction of strength was observed.

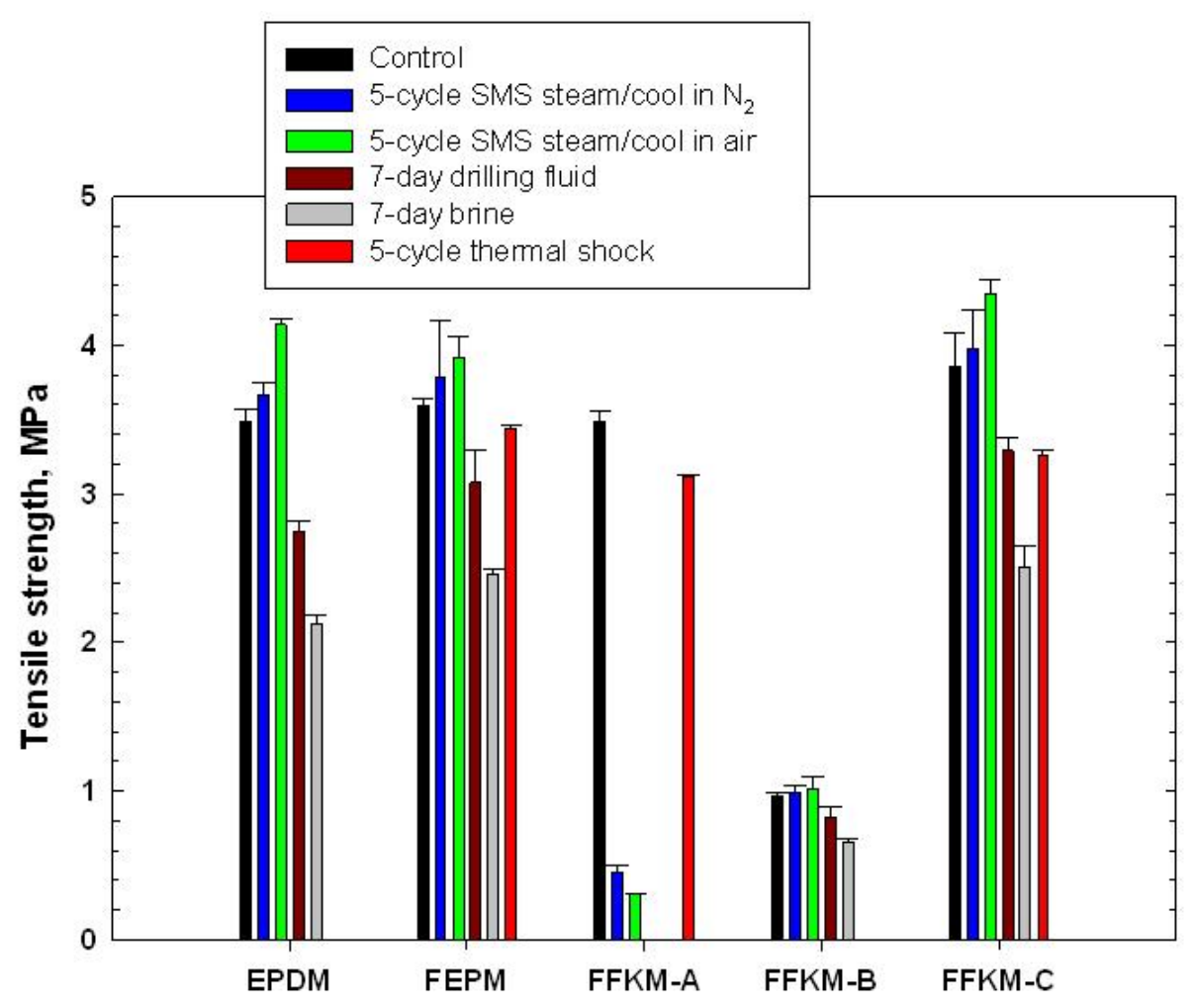

Figure 1.Tensile strength of EPDM-, FEPM-, FFKM-A, -B, and -C-based O-rings after exposure to five different environments. 
Figure 2 depicts the ultimate elongation for these O-rings before and after exposure tests. The values of elongation for all control samples ranged from as high as $326 \%$ for EPDM to as low as 189 \% for FFKM-B. Ultimate elongation is one important key factor governing the substantial stretching that is required during fitting and placing, and also in applications where the O-ring satisfactorily seals relatively large gaps under a certain pressure. Furthermore, an adequate

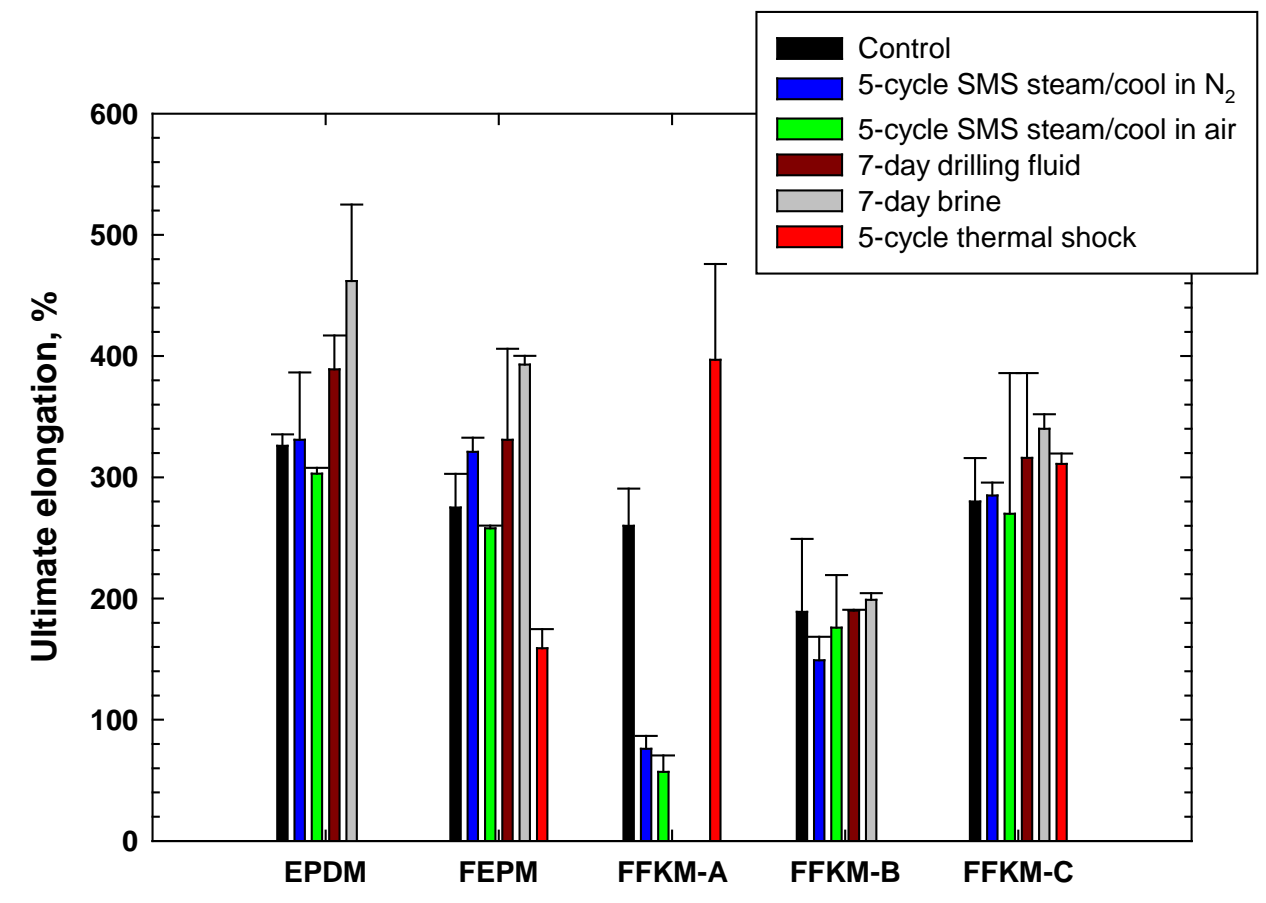

Figure 2. Ultimate elongation of EPDM-, FEPM-, FFKM-A, -B, and -C-based O-rings after exposure to five different environments.

value of elastic elongation is responsible for the rings returning quickly to their original shape after releasing a large stretching stress. Compared with that of the control, in the steam-cooling cycle environments in $\mathrm{N}_{2}$ and air, most of the O-rings without FFKM-A exhibited either an increase or no significant change, suggesting that the appropriate elastic behaviors of these Orings remained in effect. By contrast, the geo-brine fluid had the highest impact on an increasing elongation, while the extent of such an impact by the drilling fluid depended on the kind of elastomeric polymer; for instance, FFKM-B exhibited the lowest one, and relatively higher ones were observed from EPDM and FEPM. Relating this increased elongation to the results of tensile strength, since increasing elongation means an extended softening of the O-rings, correspondingly their tensile strength is reduced. From this aspect, their decreased tensile strength led to softer O-rings, reflecting their increased elongation. In the thermal shock environment, the elongation of the post-test FFKM-A and -C rose by 53 and $11 \%$, respectively, compared with that of the control. The FEPM's elongation was reduced by nearly $40 \%$, implying the conversion of its elastic nature into brittle one. Hence, as is evident from the combined results of tensile strength and ultimate elongation, although EPDM and FFKM-B exhibited good 
compatibility with all thermochemical environments, their major weakness were their vulnerability to thermal shock. Despite the weakness of FFKM-A in all thermochemical environments, it well withstood the thermal shock environment. Meanwhile, the FFKM-C nanocomposite conferred the best performance in maintaining adequate mechanical properties on the O-ring after exposure to all environments.

\subsection{ART-FTIR study}

To gain information on the degradation, stabilization, and the fouling with silicate scales of Orings made with EPDM-, FEPM-, and FFKM-based elastomeric polymers after exposure in five different harsh environments at $300^{\circ} \mathrm{C}$, our first approach was to investigate the oxidationinduced alterations of the different polymer structures by ATR-FTIR. Then, this result was used to determine whether the altered polymers are sensitive or insensitive to silica- and silicatescaling over the O-rings.

\subsubsection{EPDM}

Figure 3 shows the ATR-FTIR absorption spectra in region of 3500 to $650 \mathrm{~cm}^{-1}$. for EPDM Orings before and after being exposed to Nos.1, 3, 4, and 5 environments. The spectrum for the non-exposed O-ring as the control encompasses six representative absorption bands: Those at 2918 and $2851 \mathrm{~cm}^{-1}$ attributed to the C-H asymmetric $\left(V_{\text {as C-H}}\right)$, and symmetric $\left(V_{\text {s. C-H }}\right)$ stretching vibrations in $-\mathrm{CH}_{2^{-}}$group, respectively, at 1538 and $1394 \mathrm{~cm}^{-1}$ assigned to carboxylate group, $\mathrm{COO}^{-}$, asymmetric $\left(V_{\text {as }} \mathrm{COO}^{-}\right)$and symmetric $\left(V_{\mathrm{s}} \mathrm{coO}^{-}\right)$stretching vibrations [10-12], and at 1466 and $1365 \mathrm{~cm}^{-1}$. due to $-\mathrm{CH}_{2}$ - scissoring $\left(\delta_{\mathrm{CH} 2}\right)$ and $-\mathrm{CH}_{3}$ asymmetric bending $\left(\delta\right.$ as CH3 $\left._{3}\right)$ vibrations $[13,14]$. Since the structure commonly known as EPDM is ploy(ethylene-co-propylene-co-5-ethylidene-2-norbornene), there were no presence of carboxylate groups. Thus, this EPDM structure seems to be modified with carboxylate. When EPDM was exposed in the No. 1 environment, the spectral feature of FTIR spectrum differed from that of the control. There were four differences: First, the absorbance-peak heights of $V_{\text {as C- }}$

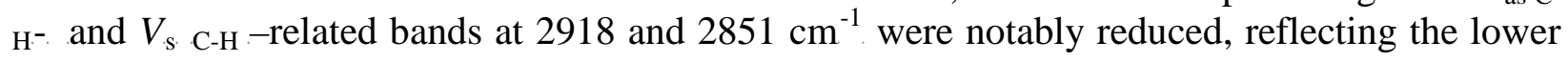
number of $-\mathrm{CH}_{2-}$ groups ; second, the absorbance of the $V_{\text {as }}$ coo $^{-}$- and $V_{\text {s }}$ coo $^{-}$- associated bands at 1538 and $1394 \mathrm{~cm}^{-1}$. was strikingly decayed; third, the $\mathrm{C}=\mathrm{C}$ stretching $\left(V_{\mathrm{C}=\mathrm{C}}\right)$ vibration derived from the oxidative degradation of polymer was appeared at $1646 \mathrm{~cm}^{-1}$. [15]; and, fourthly, the two new bands emerged at 991 and $789 \mathrm{~cm}^{-1}$. The contributor to these typical new bands was the silica-related scale precipitated directly on the O-ring's surfaces; the former band was assignable to asymmetric ( $V_{\text {as }}$ Si-O-Si) vibration of oxygen bridged Si-O-Si linkage in polymeric silica and the latter one was associated with symmetric ( $V_{\text {s }}$ Si-O-Si) stretching vibration of this Si-O-Si linkage [16-18]. A similar spectral future also was observed from O-rings exposed in the No.2 environment (not shown). After exposure in the No.4 environment (brine), more silica fouling was recognized from a marked peak at $991 \mathrm{~cm}^{-1}$, in conjunction with the appearance of absorption band at $1111 \mathrm{~cm}^{-1}$. related to the Si-O-Si linkages. However, based upon the geo-brine chemistry (Table 3 ) containing alkali metals ( $\mathrm{Na}, \mathrm{K}$ ) and alkali earth metals (Ca, Mg), it is possible to assume that the scales not only belonged to silica, but also were associated with silicate in this particular environment. Meanwhile, the O-ring was degraded, reflecting the incorporation of oxidation-induced $\mathrm{C}=\mathrm{C}$ and $\mathrm{C}=\mathrm{O}$ groups at $1646 \mathrm{~cm}^{-1}$ and 1636 $\mathrm{cm}^{-1}$, and the reduced peak intensity of $-\mathrm{CH}_{2}-$ and carboxylate groups. Since the drilling fluid 
contained a 7-5\% Ca-bentonite clay (aluminum phyllosilicate) as the source of silicate, attention was paid to silicate scale. The spectral feature of O-rings exposed to drilling fluid closely resembled that of the brine-exposed one, except for a lower intensity of the silicate-related asymmetric ( $V_{\text {as }}$ Si-O-Si $)$ and symmetric $\left(V_{s}\right.$ Si-O-Si $)$ peaks at 991 and $789 \mathrm{~cm}^{-1}$. Thus, the susceptibility of oxidized O-ring's surface to bentonite fouling may be moderate. Nevertheless, the oxidation-caused degradation of EPDM O-rings seems to promote the silica- and silicatefouling during exposure in these environments.

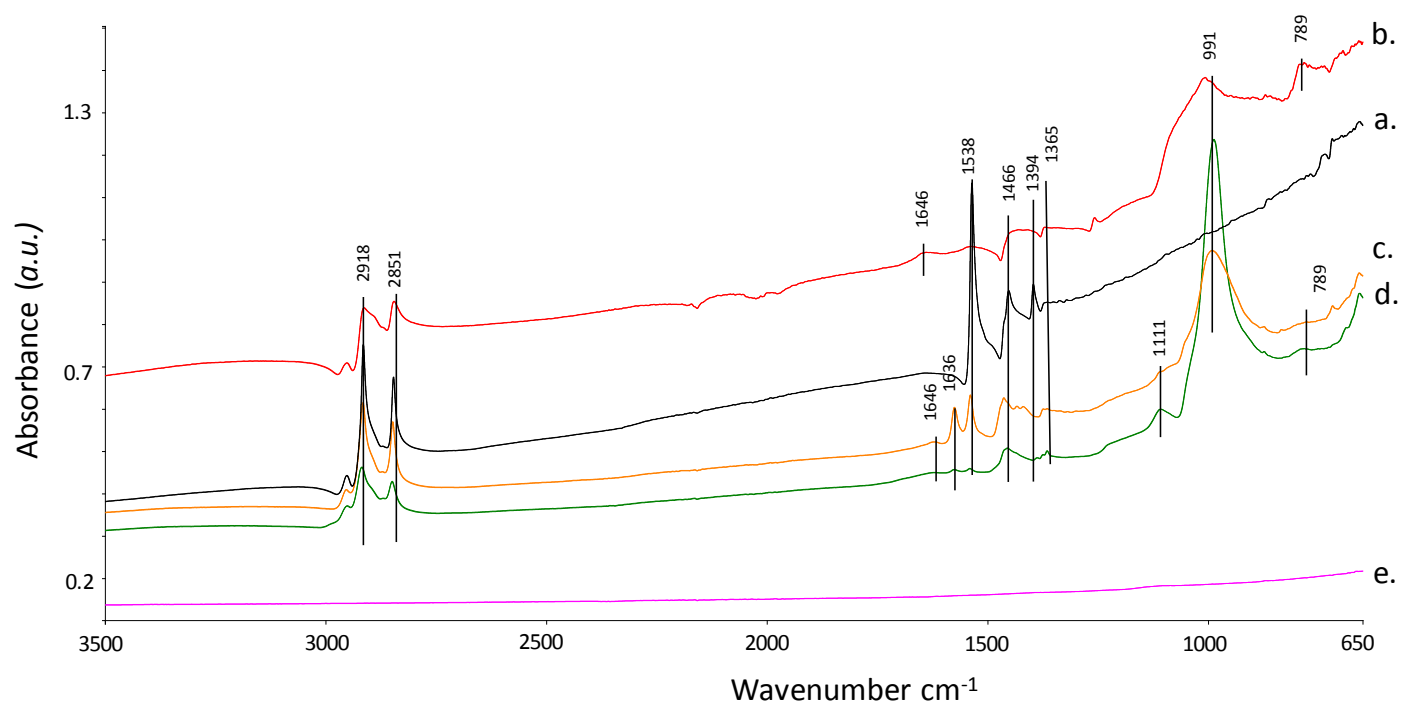

Figure 3. ATR-FTIR absorption spectra of EPDM O-rings before (a) as the control, and after (b) No. 1 SMS-containing steam-cooling cycles in $\mathrm{N}_{2}$, (c) No.3 exposure in drilling, (d) No.4 exposure in brine, and (e) No.5 after thermal shock.

On the other hand, the No.5 environment (thermal shock) was detrimental to the O-ring's integrity, resulting in its severe oxidation-initiated deterioration. Thus, the spectrum did not show any prominent peaks of hydrocarbon-related bands.

\subsubsection{FEPM}

Figure 4 illustrates the ATR-FTIR spectrum for FEPM O-rings before and after exposure in all these testing environments. Since FEPM is the copolymer consisting of poly[tetrafluoroethylene (TFE)-co-propylene (P)], according to references [19-22], the spectrum of the control literally revealed the C-H asymmetric $\left(V_{\text {as }}\right.$ C-H $)$, and symmetric $\left(V_{\mathrm{s} \text { C-H }}\right)$ absorption bands at 2916 and $2849 \mathrm{~cm}^{-1}$, respectively, the $\mathrm{CH}_{2}$ - scissoring $\left(\delta_{\mathrm{CH} 2}\right)$ in region of $1464-1441 \mathrm{~cm}^{-1}$, the C-H bending vibration $(\delta \mathrm{cH})$ at $1387 \mathrm{~cm}^{-1}$, CF $\left(V_{\mathrm{CF}}\right)$ at $1334 \mathrm{~cm}^{-1}$, C-C bond $\left(V_{\mathrm{C}-\mathrm{C}}\right)$ stretching vibration in fluorocarbon at 1263 and $1225 \mathrm{~cm}^{-1}$, and $\mathrm{CF}_{2}\left(V_{\text {as }} \mathrm{CF}_{2}\right)$ in the region of 1164-1113 $\mathrm{cm}^{-1}$ and $\mathrm{CF}_{2}$ ( $V_{\mathrm{s}} \mathrm{CF}_{2}$ ), ranging from1075 to $944 \mathrm{~cm}^{-1}$ along with the band at $793 \mathrm{~cm}^{-1}$. All fluorocarbon groups were belonged to poly(TFE) consisting of $-\mathrm{CF}_{2}-\mathrm{CF}_{2}$ - links. The bands at 1735 and $1685 \mathrm{~cm}^{-1}$. may be due to $\mathrm{C}=\mathrm{O}$ group $(V \cdot \mathrm{C}=\mathrm{O})$ in carboxylic acid, and the latter band also may overlap the $\mathrm{H}-\mathrm{O}-\mathrm{H}$ bending $\left(\delta_{\mathrm{H}-\mathrm{O}-\mathrm{H}}\right)$ in the moisture adsorbed onto the O-ring. After exposure in all these environments, like EPDM, the FEPM also suffered some oxidation-caused 
degradation because of a conspicuous reduction in the absorbance of the $-\mathrm{CH}_{2}$-related bands. Without this $-\mathrm{CH}_{2}$ - oxidation, the No.1- and 2-exposed O-rings did not show any notable changes in spectral features, compared with that of the control, and nor were prominent silicarelated peaks detected, manifesting that despite incurring the oxidation-led degradation, the magnitude of silica scaling was a very little, if any. In contrast, the No.4 brine environment caused a heavy silica- and silicate-scaling, corresponding to the appearance of an intensive absorbance peak of asymmetric $\left(V_{\text {as }}\right.$ Si-O-Si $)$ at $987 \mathrm{~cm}^{-1}$. band. Thus, the band at $793 \mathrm{~cm}^{-1}$. not only was referred to the $V_{\mathrm{s} \text { CF2 }}$, but also overlapped symmetric $\left(V_{s}\right.$ Si-O-Si $)$ stretching in Si-O-Si linkage. Such extensive silica- and silicate-scaling engendered a substantial decay of peak intensities of all the chemical groups representative of FEPM structure. A similar decay of the overall spectrum was observed from the O-ring exposed in the No.3 drilling fluid and the No.5 thermal shock environments. Hence, these environments similar to that of brine also promoted the degradation of this O-ring. Additionally, it should be noted that in drilling fluid, the absorption bands attributed to bentonite-related silicate fouling were hardly identifiable. From this result, FEPM O-ring appeared to be more susceptible in brine, drilling fluid, and thermal shock environments to oxidation-led degradation, compared with that in the SMS-steam/cooling cycle environments in both $\mathrm{N}_{2}$ and air.

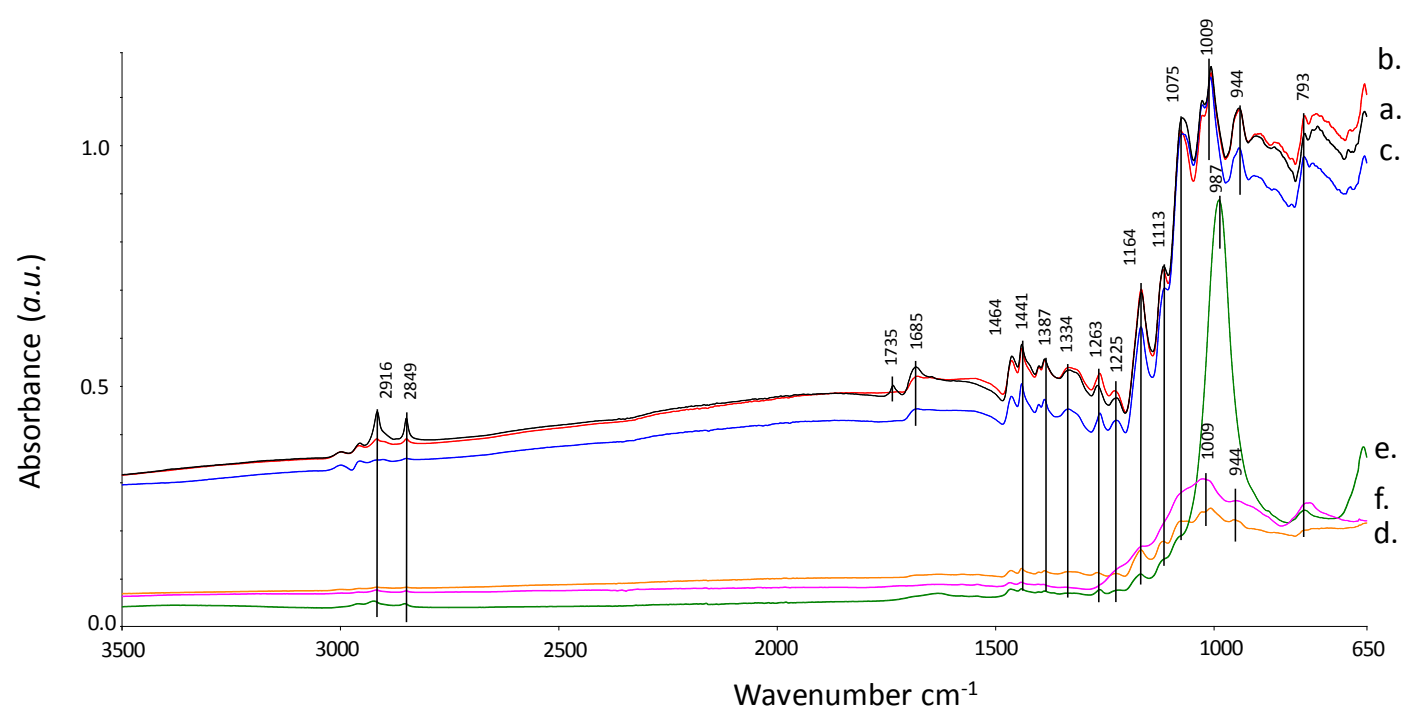

Figure 4. ATR-FTIR spectra of FEPM O-rings before (a) as the control0, and after (b) No. 1 SMS-containing steam-cooling cycles in $\mathrm{N}_{2}$, and (c) No.2 in air, (d) No.3 exposure in drilling, (e) No.4 exposure in brine, and (f) No.5 after thermal shock.

\subsubsection{FFKM}

Figure 5 depicts the ATR-FTIR spectra of the "as-received" three different FFKM-based O-rings as the control. As is evident in the spectral features, all O-rings contained the alkane formula, $\mathrm{C}_{\mathrm{n}} \mathrm{H}_{2 \mathrm{n}-2}$, because of the presence of the typical $-\mathrm{CH}_{2^{-}}$group at $2971,2853,1465$, and $1421 \mathrm{~cm}^{-1}$. Since the principal chemical structure of FFKM is the poly(TFE-co-perfluoromethylvinylether (PMVE)] copolymer, conceivably, all FFKM had ethylene (E) linkages formed by the branching and crosslinking of the fluorinated diene used in the branching and pseudo-living 
polymerization. Namely, FFKM-A and-B may be represented as an E-altered TFE structure [2326]. If this assumption is valid, these FFKMs can be described as the poly(E-alt-TFE-co-PMVE) structure. In fact, the PMVE-related groups such as -CC-, - $\mathrm{CF}_{2}$, -COC-, and - $\mathrm{CF}_{3}$ were present in the region from 1291 to $782 \mathrm{~cm}^{-1}$. The details of bands belonging to these groups were as follows: C-C bond $\left(V_{\mathrm{C}-\mathrm{C}}\right)$ stretching at $1291 \mathrm{~cm}^{-1}$ in fluorocarbons; $\mathrm{CF}_{2}\left(V_{\text {as }} \mathrm{CF2}_{2}\right)$ in $1192-1113$ $\mathrm{cm}^{-1}$ as well as at $782 \mathrm{~cm}^{-1}$; C-O-C asymmetric $\left(V\right.$ as C-O-C) at shoulder band of $1026 \mathrm{~cm}^{-1}$ [27,28]; and, $-\mathrm{CF}_{3}\left(V_{\mathrm{CF} 3}\right)$ at $889 \mathrm{~cm}^{-1}$ in either- $\mathrm{CF}_{3}$ pending groups [29]. The frequency at $1647 \mathrm{~cm}^{-1}$ is $\mathrm{H}-\mathrm{O}-\mathrm{H}$ bending $\left(\delta_{\mathrm{H}-\mathrm{O}-\mathrm{H}}\right)$ in moisture. In the case of the FFKM-C nanocomposite, the $-\mathrm{CH}_{2}-$ groups may be associated with E-branched and-crosslinked poly(TFE) nanoparticles in FFKM. Compared with the spectral feature of FFKM-A, there were two noticeable differences in this feature for FFKM-B and -C; the differences were the intensity of the ether-related shoulder band at $1026 \mathrm{~cm}^{-1}$ and the $-\mathrm{CH}_{2}$ - peak at $2971 \mathrm{~cm}^{-1}$. FFKM-A revealed the strongest signal of ether shoulder band; contrarily, FFKM-C exhibited its weakest one, highlighting that the latter O-ring was assembled by minimal ether- $\mathrm{CF}_{3}$ groups. In fact, the ranking of stronger peak intensity at $V_{\text {CF3 }} 889 \mathrm{~cm}^{-1}$. was in the order: FFKM-A $>$ FFKM-B $>$ FFKM-C. The FFKM-B had the most intensive signal of $-\mathrm{CH}_{2-}$, implying that this O-ring had a relatively high $\mathrm{E}$ content, compared with that of the other two FFKMs.

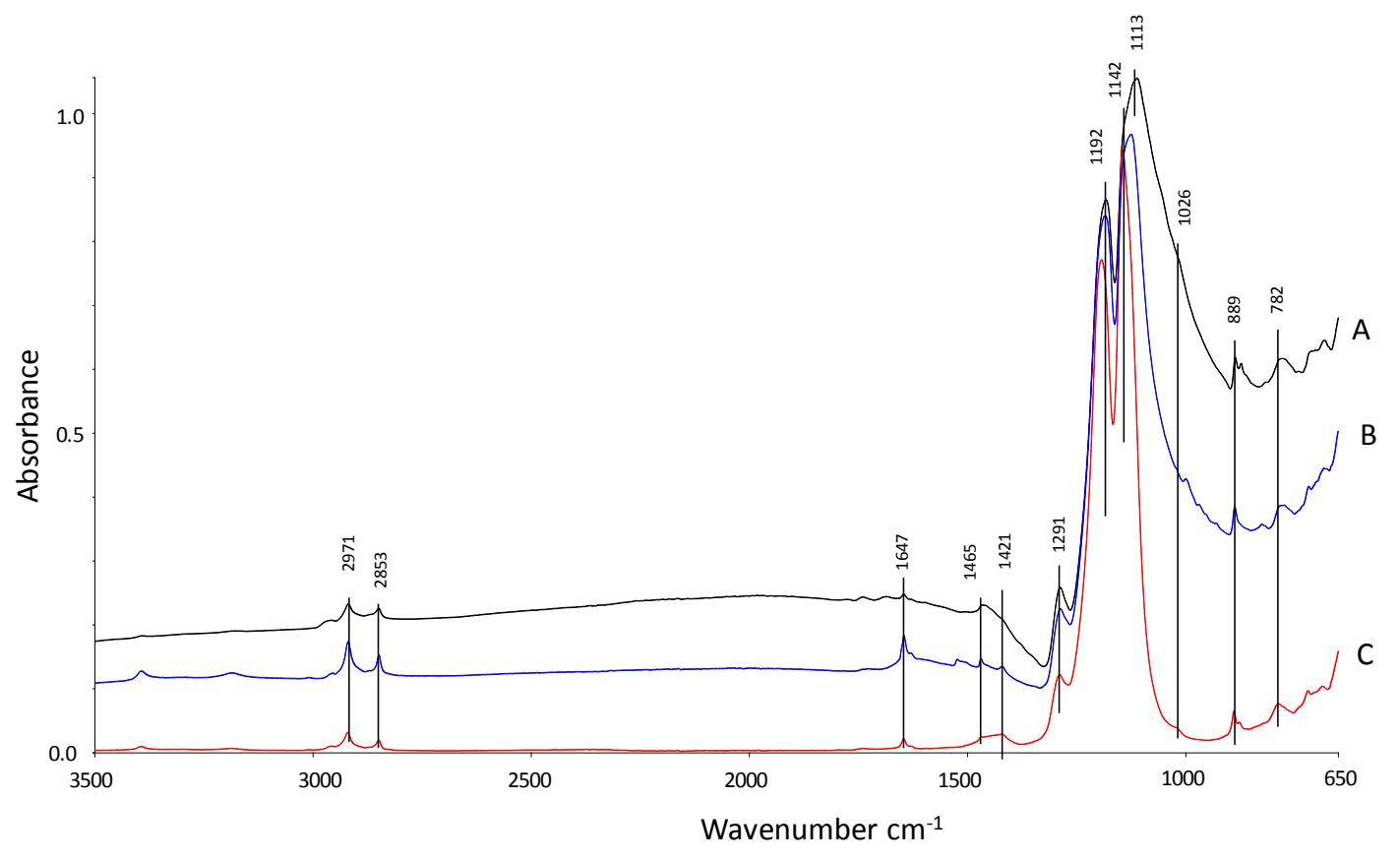

Figure 5. ATR-FTIR spectra of the "as-received" (A) FFKM-A, (B) -B, and (C) -C O-rings.

After exposure in the No. 1 environment (Figure 6), two major changes in spectral features were observed: One was a considerable reduction of the intensity of the $-\mathrm{CH}_{2^{-}}$-related peak in FFKM-B and -C, while this peak in FFKM-A had been eliminated; the other was the appearance of two silica scaling-related bands at $1005 \mathrm{~cm}^{-1}\left(V_{\text {as } \text { Si-O-Si }}\right)$ and $784 \mathrm{~cm}^{-1}\left(V_{s}\right.$ Si-O-Si $)$ for FFKM-A and $-\mathrm{B}$, but not for FFKM-C. For the former, this finding demonstrated that the E group in all 
FFKM structures was vulnerable in some different degree to SMS steam-caused degradation; especially for FFKM-A with its highest degradation. Regarding silica scaling, the sensitivity of FFKM-C surfaces to scaling was remarkably lower than that of FFKM-A and -B. No.2 environment (Figure 7) led to an increase in silica scaling for the FFKM-A and -B O-rings. The major reason for this increased scaling might be due to the promotion of the oxidation-caused degradation of these O-rings in SMS-steam in air, compared with that in $\mathrm{N}_{2}$. The worst scaling was on FFKM-A, reflecting that the silica-related band at $1008 \mathrm{~cm}^{-1}$ became the most prominent peak. On FFKM-C, like in $\mathrm{N}_{2}$, it was very difficult to detect the silica-related bands, underscoring its insensitivity to scaling.

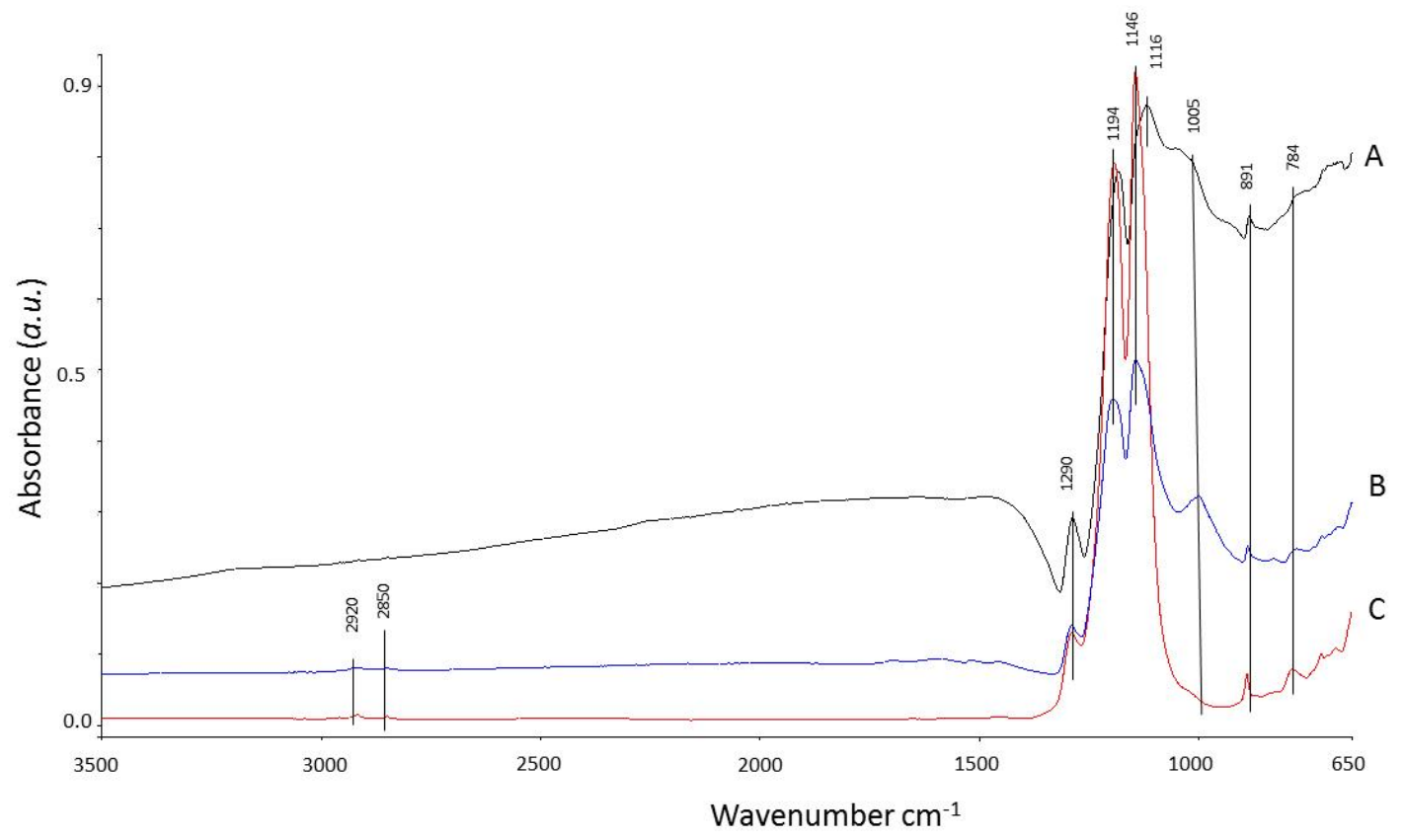

Figure 6. ATR-FTIR spectra of (A) FFKM-A, (B) -B, and (C) -C O-rings after No. 1 SMScontaining steam-cooling cycles in $\mathrm{N}_{2}$. 


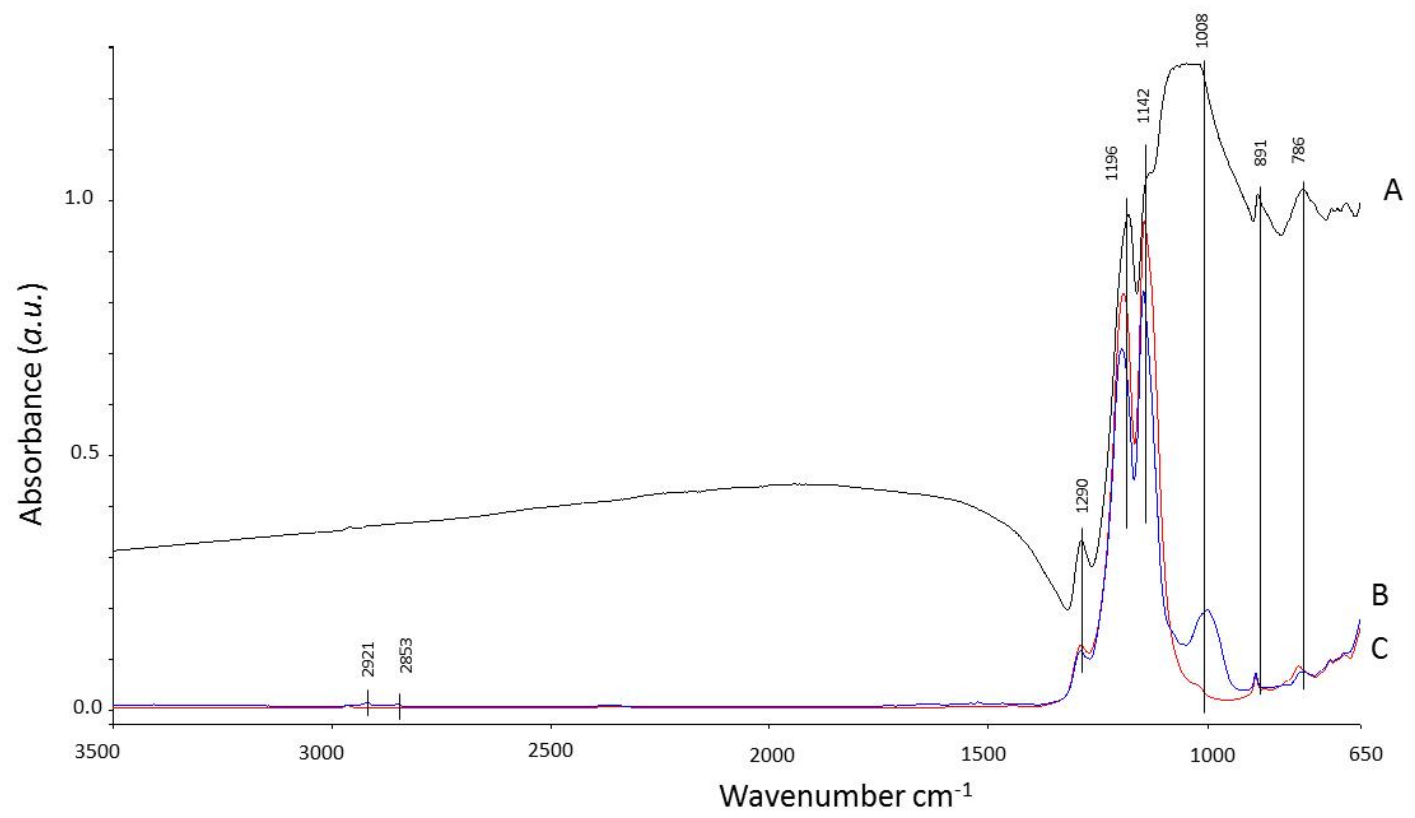

Figure 7. ATR-FTIR spectra of (A) FFKM-A, (B) -B, and (C) -C O-rings after No. 2 SMScontaining steam-cooling cycles in air.

Figure 8 gives the ATR-FTIR spectra of the FFKM-B and-C O-rings after exposure to the No.3 (drilling fluid) and 4 (brine) environments. Again, the attention was paid to whether these Orings are sensitive or insensitive to silica- and silicate-scaling in these environments. As is evident from spectral feature, the FFKM-B was very sensitive in both environments, particularly for brine, leading to the appearance of the silica-and silicate-related bands as the major peak at $1004 \mathrm{~cm}^{-1}$. Additionally, all E-related bands at 2921, 2853, 1466, and $1426 \mathrm{~cm}^{-1}$. in both environments became extremely weaker signals, verifying that FFKM-B underwent an excessive thermochemical oxidation-caused degradation. Compared with this, for FFKM-C, although silica and silicate had precipitated in both environments, the sensitivity of bentonite-based silicate scaling in drilling fluid was minimal because of a very weak signal at $1004 \mathrm{~cm}^{-1}$; furthermore, the peak intensity of $\mathrm{E}$ bands was stronger than that of FFKM-B, reflecting the greater stability of the crosslinked $\mathrm{E}$ structure. The bands in region $1580-1538 \mathrm{~cm}^{-1}$. may be pertinent to oxidation derivatives like $V_{\text {as }} \mathrm{COO}^{-}$of the $\mathrm{COO}^{-}$group yielded by the oxidation of the O-ring in these environments. Nevertheless, FFKM-C possessed a far better resistance to oxidation and silicaand silicate-scaling, compared to FFKM-B. 


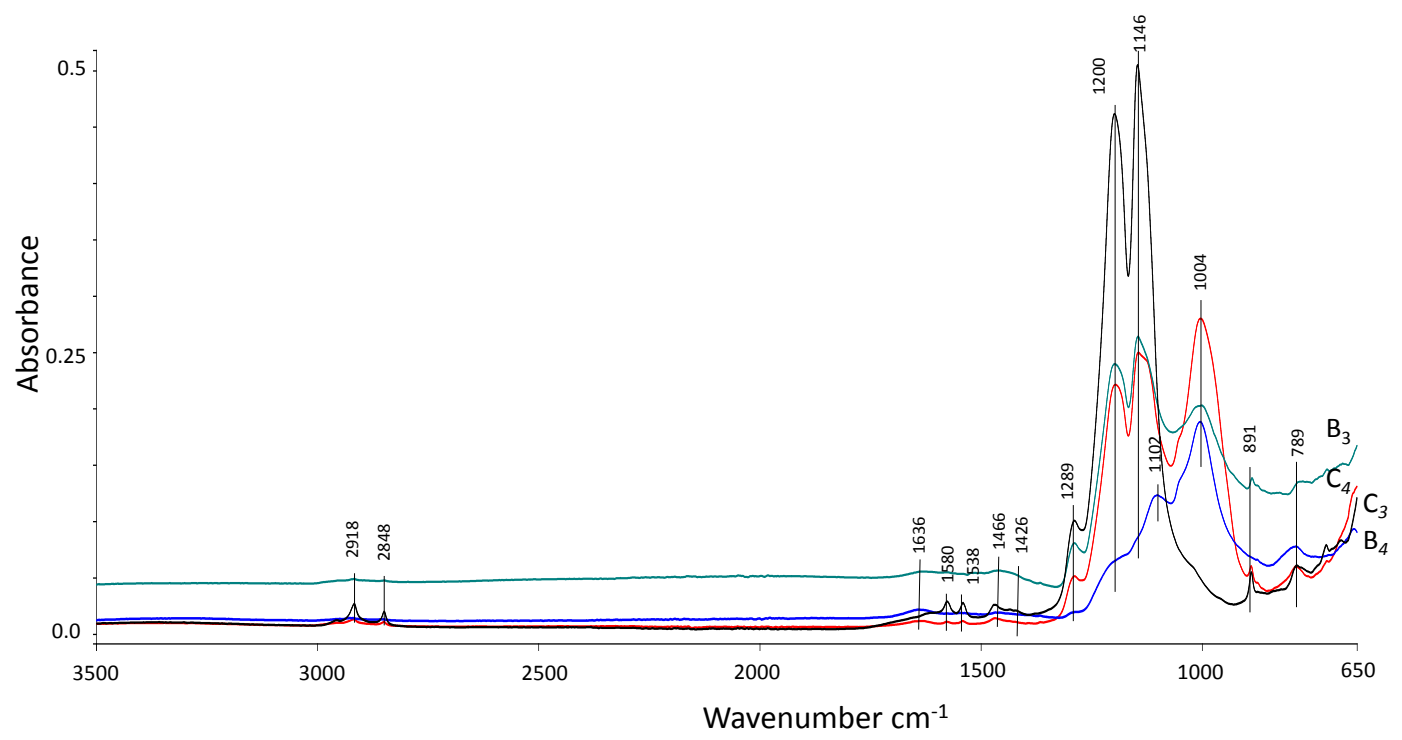

Figure 8. ATR-FTIR spectra of the FFKM-B and -C O-rings after exposure to $\left(\mathrm{B}_{3}\right.$ and $\left.\mathrm{C}_{3}\right)$ No. 3 drilling fluid and $\left(\mathrm{B}_{4}\right.$ and $\left.\mathrm{C}_{4}\right)$ No.4 brine environments.

In the No.5 environment subjected to thermal shock (Figure 9), the spectral features of two Orings made with FFKM-A and -C were similar to that of their controls, exclusive of the decay of intensity of the $-\mathrm{CH}_{2}$ - peak. In contrast, FFKM-B revealed a conspicuous alteration of spectral features. The alterations were characterized by markedly lowering the $-\mathrm{CH}_{2-}$, ether-, and $\mathrm{C}-\mathrm{C}$ (fluorocarbon)-related signal's intensity, and the emergences of three new prominent bands at 1400,938 , and $828 \mathrm{~cm}^{-1}$. The potential contributor to all new bands was a carbonated compound formed during $300^{\circ} \mathrm{C}$ heating-water quenching cycle testing; namely, these new bands were assignable to the C-O asymmetric stretching $\left(\mathrm{V}_{\text {as }} \mathrm{C}-\mathrm{O}\right)$ at $1400 \mathrm{~cm}^{-1}$ and O-C-O bending ( $\delta$ o-Co) in carbonate $\mathrm{CO}_{3}{ }^{2-}$ at 938 and $828 \mathrm{~cm}^{-1}[30,31]$. We can assume that the formation of carbonate compound is related to the carbonation of the mineral additive filled in the elastomeric polymer. As shown in Table 1, this O-ring had only one oxide compound attributed to $\mathrm{K}_{2} \mathrm{O}$. Thus, $\mathrm{K}$ oxide was carbonated to form a water-soluble potassium carbonate $\left(\mathrm{K}_{2} \mathrm{CO}_{3}\right)$ salt during the heating in atmospheric environment at $300^{\circ} \mathrm{C}$. This finding is one reason why the integrity of this O-ring was undermined in such a heating-water quenching environment.

Based upon integrating all the data described above, five factors affected the degradation of the O-rings caused by $300^{\circ} \mathrm{C}$ thermochemical environments and thermal shock: 1) The susceptibly of $-\mathrm{CH}_{2}$ - hydrocarbon groups to oxidative reactions; 2) the incorporation of oxidation derivatives, such as $\mathrm{C}=\mathrm{C}, \mathrm{C}=\mathrm{O}$, and $\mathrm{COO}^{-}$groups, into the polymer; 3 ) the difference in polymer structures; 4) the kind of mineral additives; and, 5) the composite structures. Among these factors, particular attention was paid to the first factor relevant to the decrease in the peak height of $-\mathrm{CH}_{2-}$ groups, ranging from 2913 to $2920 \mathrm{~cm}^{-1}$, of the O-rings after exposure in these environments (Figure 10). The data obtained would provide us with information on the extent of degradation of various O-rings incurred from these different environments, and whether they are compatible or incompatible with them. In the thermochemical environments, all O-rings 
exclusive of FFKM-A revealed that the decreasing rate of this peak height depended on the

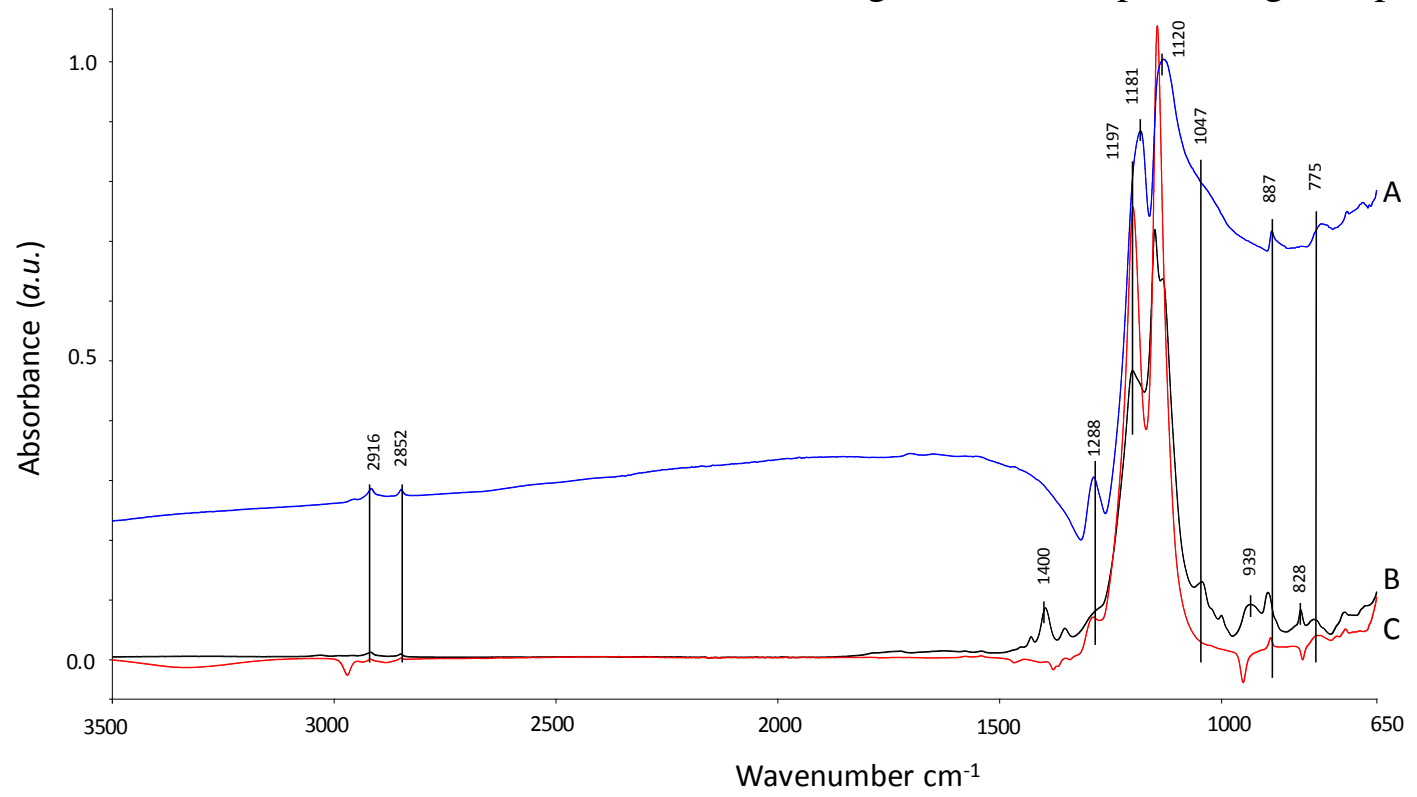

Figure 9. ATR-FTIR spectra of (A) FFKM-A, (B) -B, and 2 (C) -C O-rings after No.5 thermalshock cycle testing.

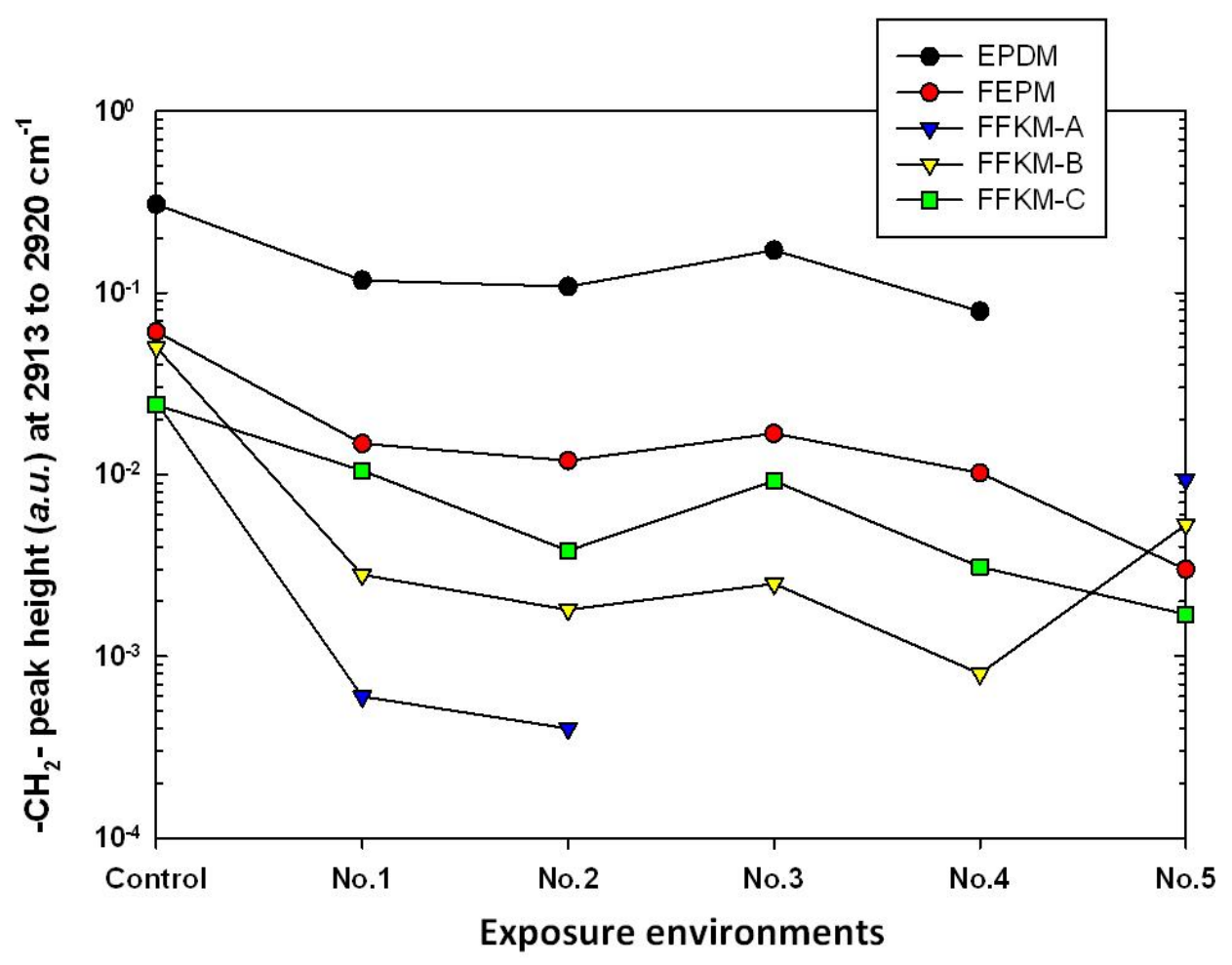

Figure10. Changes in the $-\mathrm{CH}_{2}$ - peak height of various O-rings exposed in five different environments. 
environments; the highest rate occurred in No.4 brine. Next higher rate was in No.2 SMS steam in air, while No.3 drilling fluid provided the lowest one.

Hence, the chemical reactivity of drilling fluid containing organic polymers with O-rings may differ from that of the other thermochemical environments without any organic chemical components. If this concept is valid, the drilling fluid preferentially reacts with the other chemical groups in the O-rings, rather than that with $-\mathrm{CH}_{2-}$. Also, the decreasing rate of $-\mathrm{CH}_{2^{-}}$ peak intensity depended on elastomeric polymer structures, for instance, in the No.2 environment, this lower rate was ranked in the following order; EPDM (64.7\%) > FEPM (80.5\%) >FFKM-C (84.2\%) >FFKM-B (96.4\%) >FFKM-A (98.4\%). By contrast, the No.5 thermal shock environment was quite different from the thermochemical environments; namely, the ranking of this lower decreasing rate was in order; FFKM-A (62.4\%) >FFKM-B (89.4\%) $>$ FFKM-C (92.9\%) > FEPM (95.1\%) > EPDM (100\%).

\section{3. $\mu E D X$ analysis for silica- and silicate-fouling}

To support information on silica- and silicate-scaling obtained from FTIR study and to visualize these scaling, focus next centered on conducting $\mu$ EDX topographical mapping analysis of the scale precipitated on the O-ring's surface for the same samples used in the FTIR study. The Si element, particularly for the $1.74 \mathrm{keV}$ spectral resolution at the Si $K \alpha$ energy line, was employed in this topographical mapping analysis. During mapping, the X-ray-intensity count in the total detected area of $3 \mathrm{~mm}^{2}$. was recorded and used to estimate a relative amount and distribution of this element based on creating a color-coded concentration map, so enabling us to rank the concentration of this element by the difference in colors.

Figure 11 shows the $\mu$ EDX maps of Si for EPDM, FEPM, FFKM-A, -B, and -C O-rings after exposure in the No. 1 environment. In the texture of this mapping image, the triangle-shaped signals and their heights and asperities emerging on the mesh-shaped underlying O-ring surfaces represent the distributions and the magnitude of an accumulation of scaling. Furthermore, the relative amount of scaling can be estimated from color barcode; namely, if the triangular signal shows the color in orange, it symbolizes the relatively highest concentration of scaling. As opposed to this, a dark blue color is assigned to its lowest scaling rate. The data revealed that FFKM-A surface was extensively covered by scaling, some of which this high-concentration and -accumulation can be recognized from a random distribution of copious tall light blue-colored triangles. FKM-C had this lowest coverage, which is denoted as the scattering of a few short blue-color triangles, while the rest of the O-rings exhibited a moderate coverage. Compared with these images, the No.2 environment (Figure 12) clearly verified that aerated SMS steam significantly enhanced the precipitation of additional scaling for all O-rings; in fact, not only did the number and height of the triangular signals increase over the entire surface area, but also the distribution of more bright-blue-and orange-colored signals representing a high concentration level of scaling was detected. Hence, this data strongly supported the FT-IR results; namely, aerated steam enhanced the rate of scaling compared with that of in $\mathrm{N}_{2}$. Based upon the comparison between the number, height, and color of signals, the ranking of an increased scaling rate is in following order; FFKM-A $>-\mathrm{B}>-\mathrm{C}=\mathrm{EPDM}=\mathrm{FEPM}$. Relating this result to the decreasing rate of $-\mathrm{CH}_{2}$ - peak intensity obtained in FT-IR study, the relative scaling rate is likely 
to be correlated directly with the susceptibility of $-\mathrm{CH}_{2}$ - group to oxidation-caused degradation in different environments. In fact, the ranking of this susceptibility was responsible for the
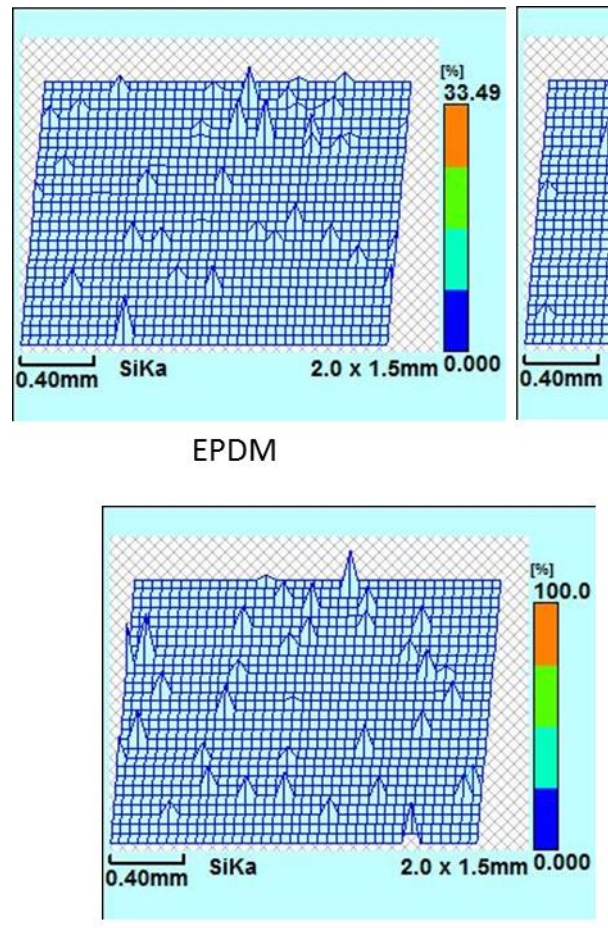

FFKM-B

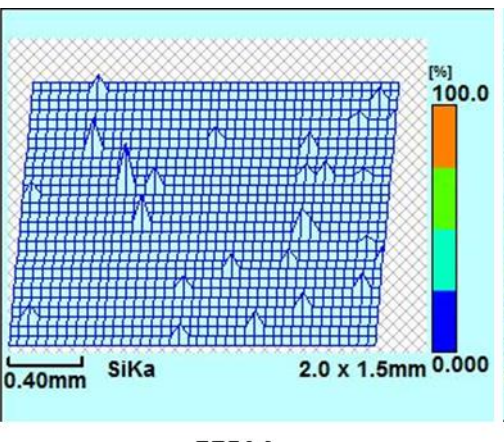

FEPM

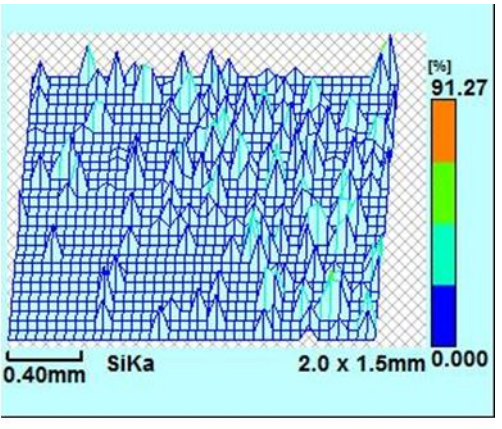

FFKM-A

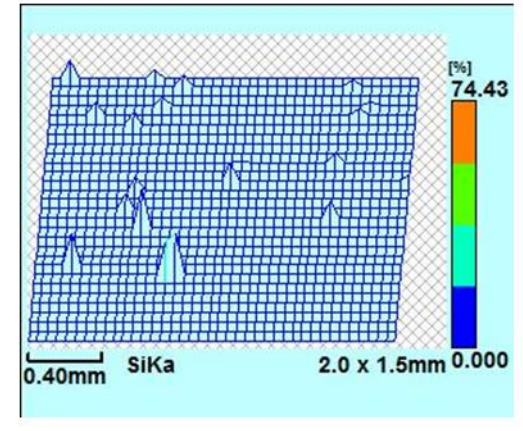

FFKM-C

Figure 11. EDX mapping of Si element attributed to silicate fouling precipitated on EPDM, FEPM, FFKM-A, -B, and -C O-ring's surface after exposure in SMS steam-cooling cycle in $\mathrm{N}_{2}$.

magnitude of scaling rate; the surface of FFKM-A possessing the highest susceptibility of this group had its most extensive coverage, while, on the contrary, the EPDM, FEPM, and FFK-C with the lower susceptibility disclosed a minimum coverage. In studying the mitigation of silicaand silicate-scaling, several investigators [32-34] reported that the polyamine- and polyammonium-based cationic polymers promoted the solubility of silica and silicate, and also inhibited the growth of these scales because the positive charge sites in polymers acted to inhibit the polymerization of silicic acid containing hydroxyl groups. Furthermore, the Si centers in silica and silicate reacted with the anionic species, such as the $-\mathrm{COO}^{-}$and $-\mathrm{PO}_{3}{ }^{2-}$. present in the solid state or solution. Thus, it is reasonable to rationalize that the oxidized surfaces of the Orings surfaces containing the carboxylate group as the oxidation derivative perhaps possess chemical affinity with silicate scale, so promoting the precipitation of the scale. 


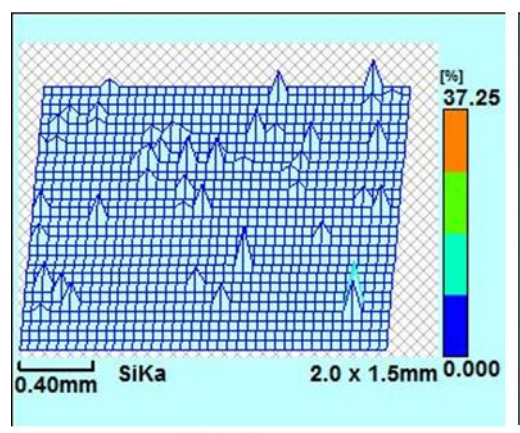

EPDM

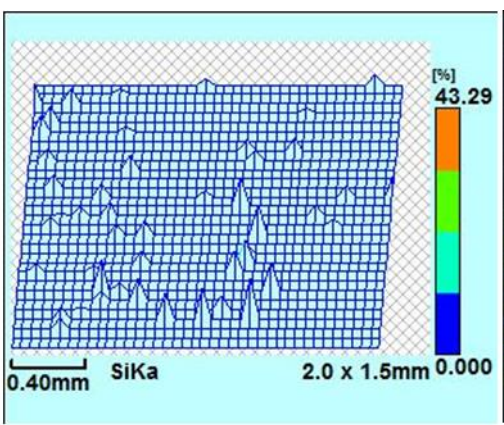

FEPM

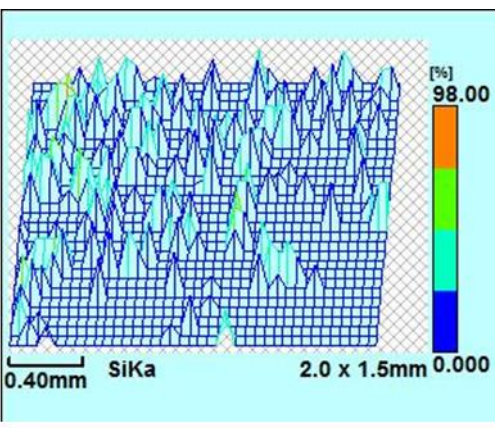

FFKM-A

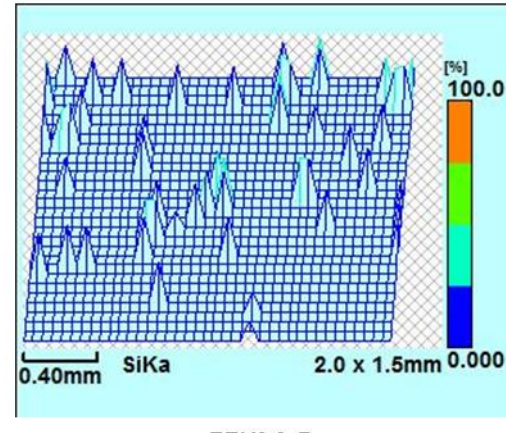

FFKM-B

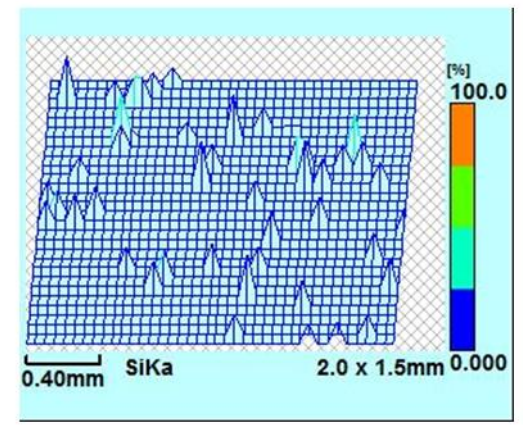

FFKM-C

Figure 12. EDX mapping of Si element attributed to silica- and silicate-scaling precipitated on various O-rings’ surfaces after exposure in an aerated SMS steam-cooling cycle.

Figure 13 compares the Si mapping and image analyses for the brine-exposed EPDM, FEPM, FFKM-B and $-\mathrm{C}$ O-rings. As illustrated, this environment aggressively promoted scaling on all of the O-rings, in particular; the image of FFKM-B was characterized by disclosing the precipitation of dense, thick scale layer on the entire O-ring surfaces (seen in photo). Compared with this, the entire surface of EPDM was covered with fine scales. A similar appearance to that of EPDM also was observed from FEPM and FFKM-C (not shown). 


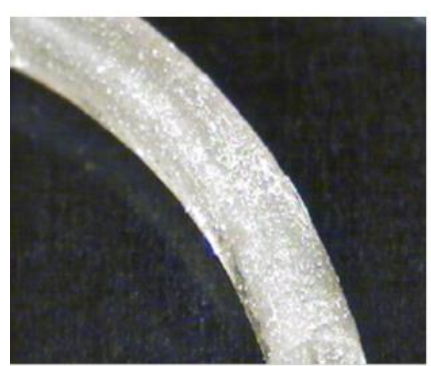

EPDM

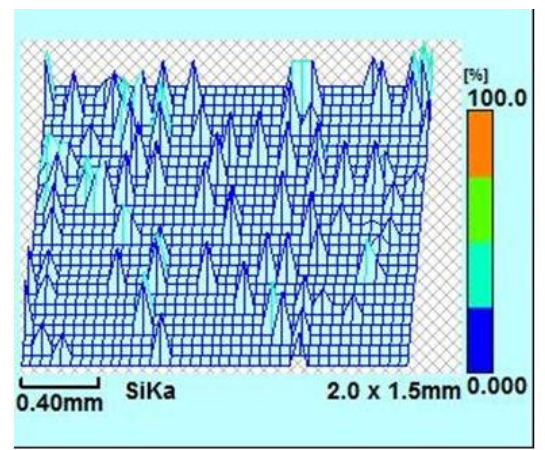

EPDM

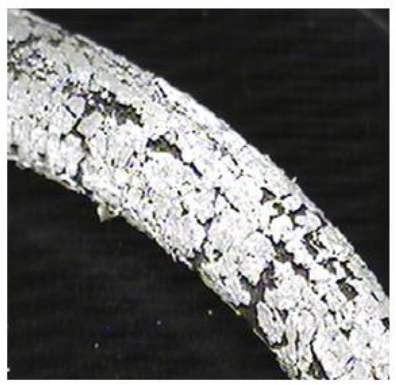

FFKM-B

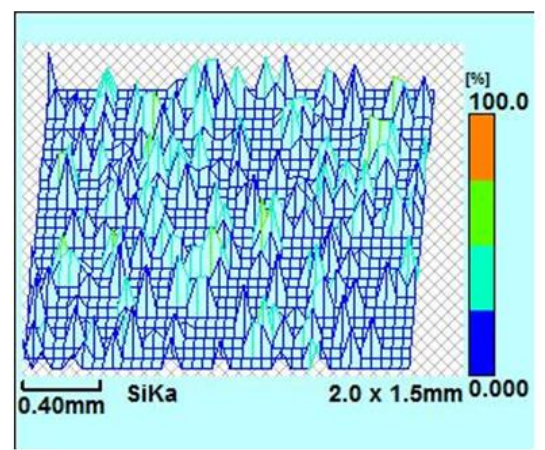

FFKM-B

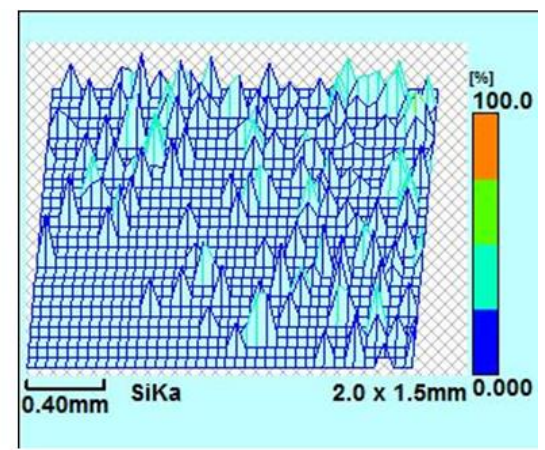

FEPM

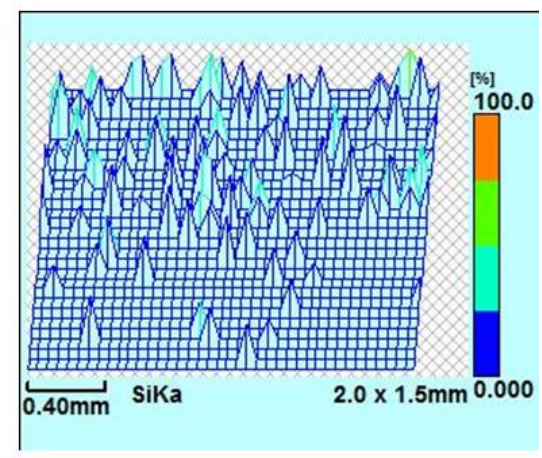

FFKM-C

Figure 13. EDX mapping of Si, and image analysis for EPDM, FEPM, FFKM-B, and -C O-rings after exposure in brine.

\subsection{DTG study}

Our attention next was shifted to the oxidative degradations of O-rings after exposure to these five environments. The following three subjects were considered as key factors governing such degradation: 1) The water uptake by the degraded O-ring, and the mineral additives; 2) the shift in the major decomposition temperature; and, 3) the changes in the rate of loss of total mass during the entire thermal decomposition. The derivative thermogravimetry (DTG) at temperatures of up to $700^{\circ} \mathrm{C}$ was employed to obtain these data.

\subsection{1. “As-received" $O$-rings}

Figure 14 depicts the DTG-thermograms for the "as-received" EPDM, FEPM, FFKM-A, -B-, and $-\mathrm{C}$ O-rings as the control. For the EPDM and FFKM-C, the DTG curve showed that there were two degradation temperatures: One was the peak $\left(T_{d 1}\right)$ as the minor degradation temperature at $311^{\circ}$ and $536^{\circ} \mathrm{C}$ for EPDM and FFKM-C, respectively; the other was the peak $\left(T_{d 2}\right)$ as the major one at $472^{\circ}$ and $475^{\circ} \mathrm{C}$. Comparisons of the major degradation temperatures (MDTs) showed that among these O-rings, FEPM possessed the highest $M D T$ at $507^{\circ} \mathrm{C}$, while all other O-rings ranged from 476 to $465^{\circ} \mathrm{C}$. The total mass loss rate, TMLR $(\% / \mathrm{min})$ was gained by computing the total area under the curve using the baseline between the curve's onset and end. 
In the cases of EPDM and FFKM-C, the value of TMLR was sum of curve $\left(T_{d 1}\right)$ and curve $\left(T_{d 2}\right)$. The value of TMLR for EPDM, FEPM, FFKM-A,-B, and -C, respectively, was 37.5, 63.1, 73.9, 62.2 , and $84.1 \% / \mathrm{min}$. For all O-rings, there was no pre-absorbed moisture, which was detectable in the thermal decomposition peaks emerging in the temperature range of $50^{\circ}-180^{\circ} \mathrm{C}$.

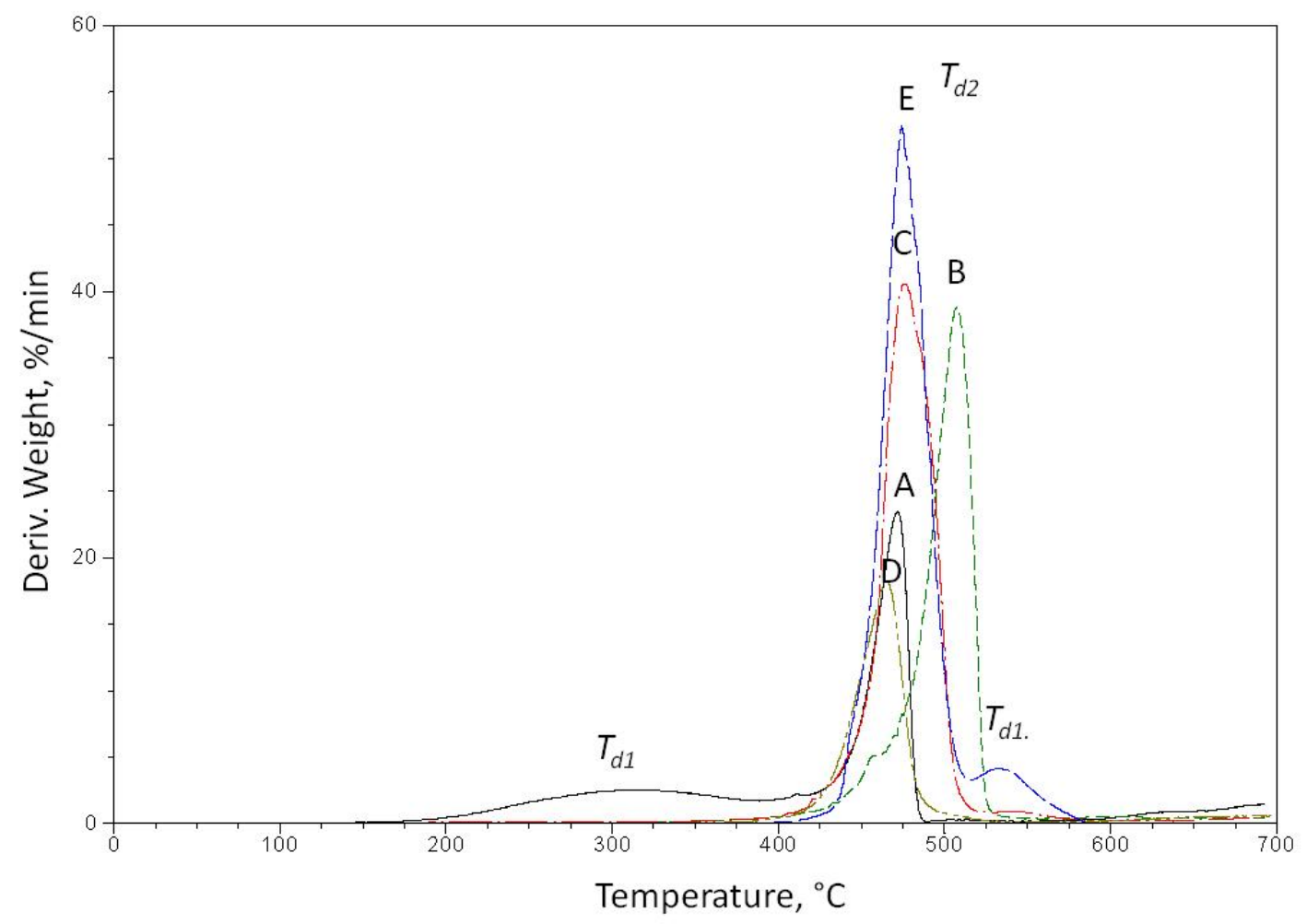

Figure 14. DTG thermograms for "as received" (A) EPDM, (B) FEPM, (C) FFKM-A, (D)-B, and (E)-C O-rings as the control.

\subsubsection{SMS steam-cooling cycle in $N_{2}$ and air}

In $\mathrm{N}_{2}$ environment (Figure 15), a considerable attention was paid to the uptake of water by the $\mathrm{O}$-rings and the change in the value of TMLR. The data revealed that three O-rings made with FEPM, FFKM-A and -B allowed them to absorb a certain amounts of water during testing, corresponding to 2.4, 2.7, and 14.9\% water absorption (WA), respectively. Although there was no experimental evidence from this limited data, the WA by post-test O-rings may be due to two likelihoods: One was a structural defect caused by the degradation of the O-rings, allowing steam to permeate through them; the other was water uptake by the mineral fillers present in degraded and/or intact O-rings. For the former case, if such a defect occurs, one concern is the creation of an undesirably rough surface texture that might cause the scale to adhere mechanically to O- 
ring's surfaces. For the latter, the rich $\mathrm{CaO}-, \mathrm{ZnO}$-, and $\mathrm{K}_{2} \mathrm{O}$-related mineral additives attributed to FEPM, FFKM-A and -B, respectively, might absorb the water under the 8.3 MPa pressure. In contrast, EPDM-and FFKM-C-made O-rings did not reveal any WA, reflecting no serious structural damage and a good compatibility with this environment. Thus, the water uptake by Orings was one critical issue to be addressed for evaluating the integrity of O-rings because of the loss of their sealing effect. On TMLR, their value of FEPM declined by $5.6 \%$ from $63.1 \% / \mathrm{min}$. before testing to $59.6 \% / \mathrm{min}$. after testing. Such a reduction was related to the presence of some

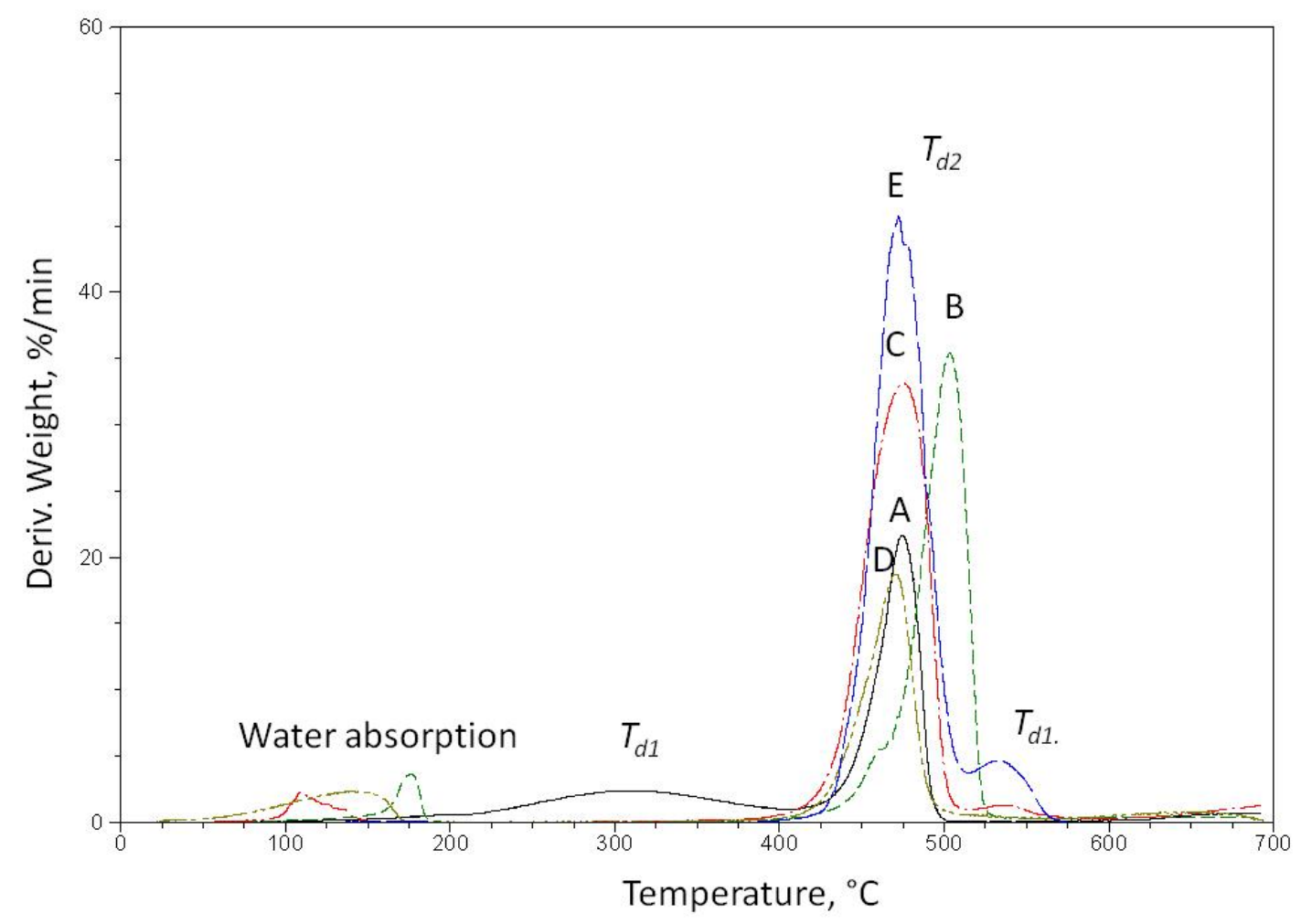

Figure 15. DTG thermograms for (A) EPDM, (B) FEPM, (C) FFKM-A, (D)-B, and (E)-C Orings after exposure in SMS steam-cooling cycles in $\mathrm{N}_{2}$.

oxidation derivatives formed by the oxidative degradation of FEPM, although ATR-FTIR did not show clearly any oxidation derivatives. According to the literature [35], these derivatives are converted into carbonaceous by-products that act to slow down the rate of loss from thermal decomposition of the O-ring. Thus, the rapid conversion of oxidation derivatives to carbonaceous by-products played a pivotal role in reducing the TMLR value. Based upon this aspect of oxidation derivative $\rightarrow$ carbonaceous by-product transformation, a secondary higher reduction of $2.3 \%$ was observed from FFKM-A. Two other O-rings, FFKM-B and-C, had a few reductions of only $0.5 \%$, while it increased by $6.7 \%$ for EPDM. For the latter, regardless of the appearance of oxidation derivatives like $\mathrm{C}=\mathrm{C}$ groups in the ATR-FT-IR results, this increase may be due to an alternation in its molecular structure during exposure to this environment. In other words, such unknown structural alternation not only enhanced the loss rate from thermal decomposition, but 
also was responsible for minimizing the formation of oxidation derivatives. On the other hand, there were no significant changes in the MDT for all O-rings.

In air, enhanced environmental oxidation led to a more uptake of water by FEPM, FFKM-A and $-\mathrm{B}$, and a further decline of TMLR value for FEPM and FFKM-A, but not for FFKM-B (Figure 16). Thus, the WA of FFKM-B in both aerated and non-aerated $\left(\mathrm{N}_{2}\right)$ steams was dependent on the water uptake by the $\mathrm{K}_{2} \mathrm{O}$-based mineral present in this O-ring, but was independent of its oxidation. In fact, the TMLR values of 61.9 and $62.1 \% / \mathrm{min}$ for $\mathrm{N}_{2}$ and air, respectively, is very close to that of the control $(62.2 \% / \mathrm{mim})$. In contrast, EPDM and FFKM-C showed no water uptake, nor was there a significant change in the TMLR value, strongly demonstrating that these O-rings possessed an excellent resistance to aerated SMS steam-caused oxidation, thereby sustaining their integrity. The MDT values for all O-rings were similar to that in $\mathrm{N}_{2}$.

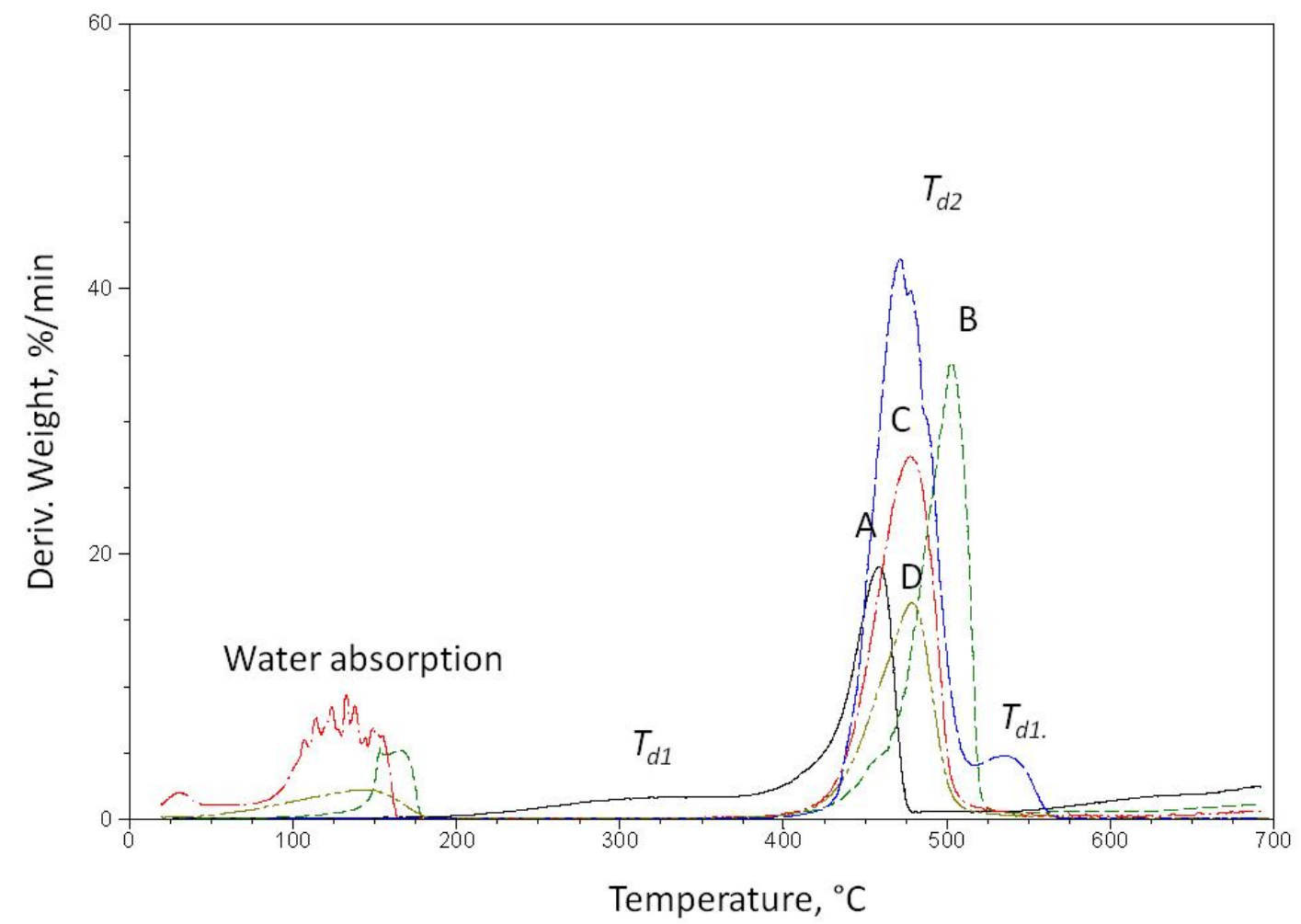

Figure 16. DTG thermograms for (A) EPDM, (B) FEPM, (C) FFKM-A, (D)-B, and (E)-C Orings after exposure in SMS steam-cooling cycles in air.

\subsubsection{Drilling fluid and brine}

Figure 17 depicts the DTG-thermograms for the EPDM, FEPM, FFKM-B, and -C O-rings after exposure to drilling fluid. Of particular interest was the TMLR value of EPDM; it was reduced by $4.8 \%$ to $35.7 \% / \mathrm{min}$. from $37.5 \% / \mathrm{min}$, suggesting that a certain amount of oxidation derivatives 
which are convertible into carbonaceous by-products had formed in the O-ring. Meanwhile, the water uptake by this O-ring was negligible, and the $M D T$ value was the same as that of the control. For FEPM, the TMLR value was further reduced to $55.7 \% / \mathrm{min}$. from the $57.1 \% / \mathrm{min}$. value of that exposed to an aerated steam, and this O-ring absorbed 3.6\% water. Despite uptake of $12.5 \%$ water, FFKM-B had a similar TMLR value to that of the control, supporting the finding that this uptake was due to the mineral filler, but not to the drilling fluid chemical-led degradation of the polymer. FFKM-C exerted an outstanding resistance to drilling fluid, reflecting neither water uptake nor a conspicuous reduction in the TMLR value. For all O-rings, the change in the $M D T$ value was minor. In brine environment, the DTG-thermograms (not shown) of all O-rings revealed similar features to that of drilling fluid-exposed ones, except for a further increased $W A$ value and a reduced TMLR value, demonstrating that the additional oxidation derivatives were incorporated into all the O-rings.

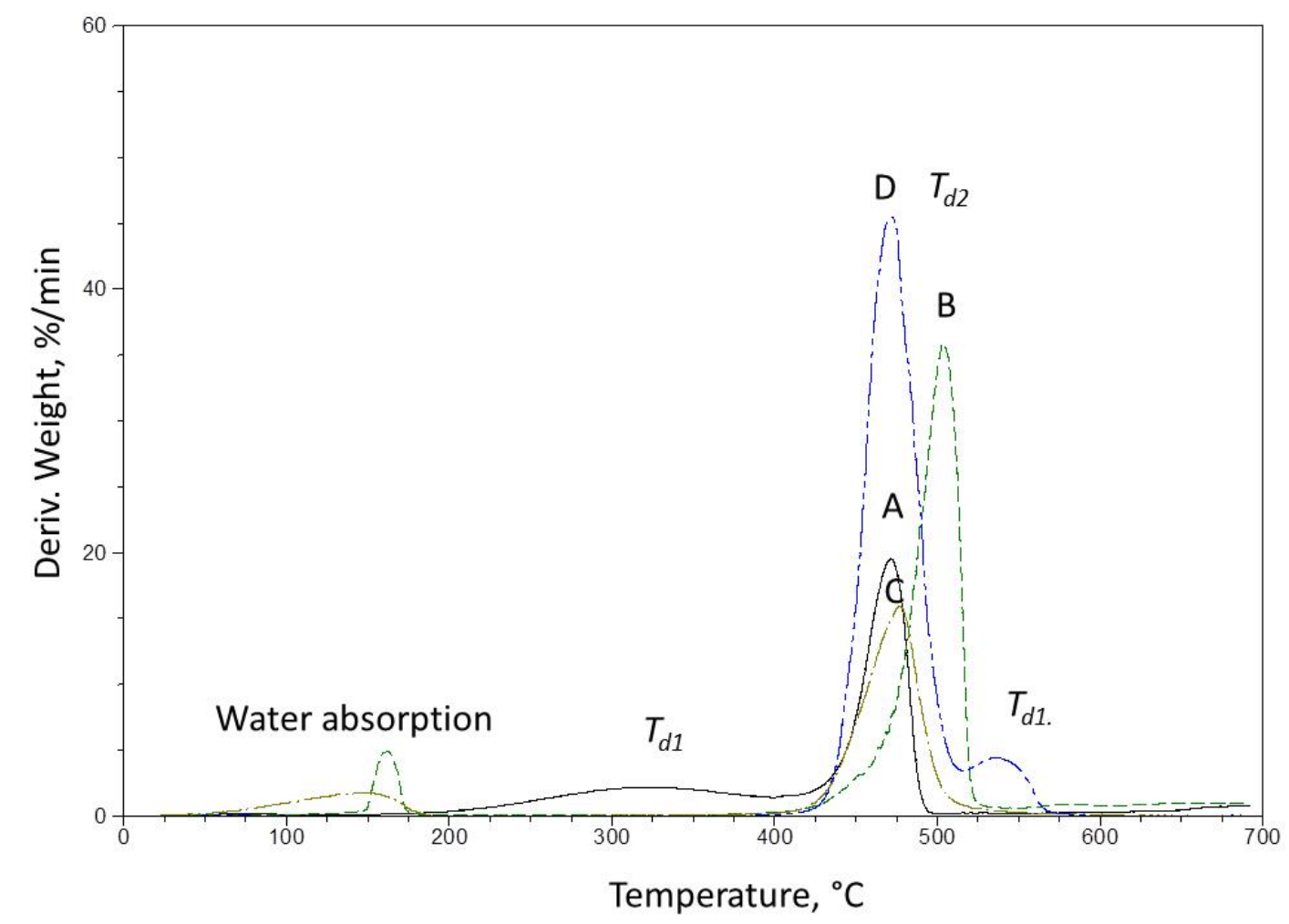

Figure 17. DTG thermograms for (A) EPDM, (B) FEPM, (C) FFKM-B, and (D)-C O-rings after exposure in drilling fluid.

\subsubsection{Thermal shock}

Figure 18 shows the DTG-thermograms for the EPDM, FEPM, FFKM-A, -B, and -C O-rings after thermal shock testing. For EPDM, this environment was detrimental to sustaining the integrity of O-ring from severe oxidation-induced degradation. Hence, the DTG curve revealed a typical decomposition pattern of carbonaceous by-product-rich compounds, along with minimum decomposable organic compounds, so describing by three degradation factors, 1) a considerable 
reduction of the $T M L R$ value to $2.6 \% / \mathrm{min}$. from $37.5 \% / \mathrm{min}$. of the control, 2) a decrease of $M D T$ to $437^{\circ} \mathrm{C}$ from $472^{\circ} \mathrm{C}$ of the control, and 3) a $W A$ of $2.8 \%$ in the water-quenching processes. Likewise, the MDT of FEPM also fell by nearly $4 \%$ to $488^{\circ} \mathrm{C}$ from $507^{\circ} \mathrm{C}$, while the TMLR value showed the lowest $52 \% / \mathrm{min}$. compared with that of this O-ring exposed to all other environments. Correspondingly, although the appearance of the O-ring remained unchanged, the FEPM was susceptible to thermal shock-led oxidation. The FFKM-A showed the most promising resistance to thermal shock in response to a pronounced increase of the MDT and TMLR values, suggesting that the FFKM-A type O-ring has a high potential for application in such a thermal shock environment. Like EPDM, the integrity of FFKM-B O-ring was undermined in this environment, although there was no change in its $M D T$ value and a reduction by $8.2 \%$ of the $T M L R$ value over that of control. As described in FT-IR study, the major reason for undermining of O-ring was due to the in-situ transformation of the $\mathrm{K}_{2} \mathrm{O}$ filler into water-soluble $\mathrm{K}$ carbonate in this environment, and followed by the leaching of the dissolved carbonate from O-ring, but not the oxidation-caused degradation of polymer itself. The thermal properties of FFKM-C were similar to those of FFKM-B, reflecting the same reduction rate of TMLR, and no marked change in $M D T$ value.

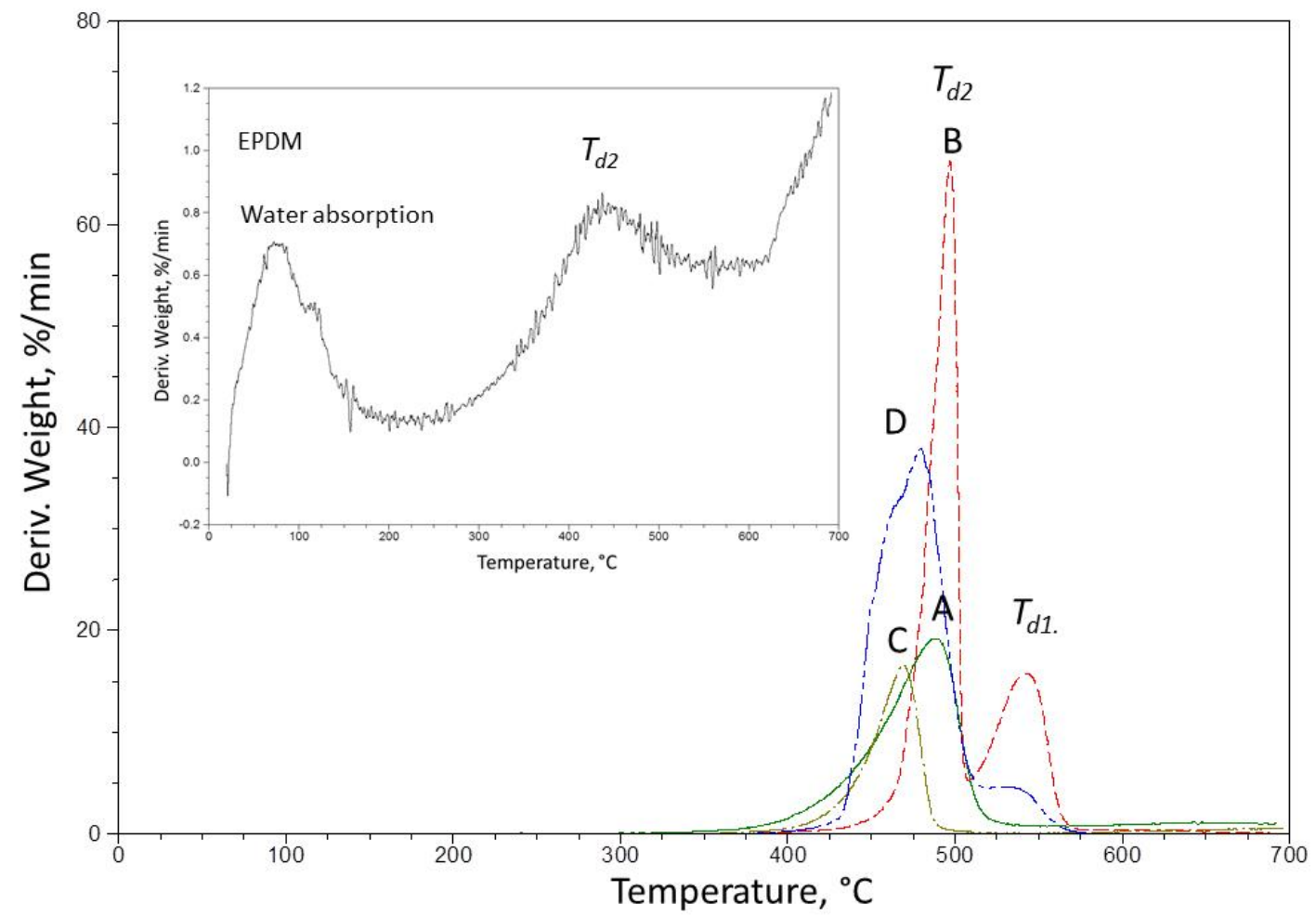

Figure 18. DTG thermograms for EPDM, (A) FEPM, (B) FFKM-A, (C)-B, and (D)-C O-rings after thermal shock cycle test.

All the data described above are summarized in Tables 2 and 3. 
Table 2. Comparison of the MDT, TMLR, and WA values for EPDM, FEPM, FFKM-A, -B, and $\mathrm{C}$ before and after exposure to SMS steam-cooling cycles in $\mathrm{N}_{2}$ and air.

\begin{tabular}{|c|c|c|c|c|c|c|c|c|}
\hline & \multicolumn{2}{|l|}{ Control } & \multicolumn{3}{|c|}{ Steam in $\mathrm{N}_{2}$} & \multicolumn{3}{|c|}{ Steam in air } \\
\hline & $M D T^{*},{ }^{\circ} \mathrm{C}$ & $\begin{array}{l}\text { TMLR }{ }^{* *}, \\
\% / \min .\end{array}$ & $\begin{array}{l}W A^{* * *}, \\
\%\end{array}$ & $M D T,{ }^{\circ} \mathrm{C}$ & $\begin{array}{l}T M L R, \\
\% / \min .\end{array}$ & $\begin{array}{l}W A, \\
\%\end{array}$ & $M D T,{ }^{\circ} \mathrm{C}$ & $\begin{array}{l}\text { TMLR, } \\
\% / \mathrm{min} .\end{array}$ \\
\hline EPDM & 472 & 37.5 & 0.0 & 475 & 40.0 & 0.0 & 469 & 41.4 \\
\hline FEPM & 507 & 63.1 & 2.4 & 504 & 59.6 & 6.1 & 502 & 57.1 \\
\hline FFKM-A & 476 & 73.9 & 2.7 & 475 & 72.2 & 19.4 & 478 & 55.9 \\
\hline FFKM-B & 465 & 62.2 & 14.9 & 469 & 61.9 & 16.0 & 479 & 62.1 \\
\hline FFKM-C & 475 & 84.1 & 0.0 & 472 & 83.7 & 0.0 & 471 & 83.7 \\
\hline
\end{tabular}

${ }^{*} M D T$ : Major decomposition temperature; ${ }^{*} T M L R$ : Total mass loss rate; ${ }^{* * * W A: ~ W a t e r ~ a b s o r p t i o n . ~}$

Table 3. Change in the MDT, TMLR, and WA values for EPDM, FEPM, FFKM-A, -B, and -C after exposure to drilling fluid- and brine, and thermal shock-cycle tests.

\begin{tabular}{|c|c|c|c|c|c|c|c|c|c|}
\hline & \multicolumn{3}{|c|}{ Drilling fluid } & \multicolumn{3}{|l|}{ Brine } & \multicolumn{3}{|c|}{ Thermal shock } \\
\hline & $\begin{array}{l}W A, \\
\%\end{array}$ & $M D T,{ }^{\circ} \mathrm{C}$ & $\begin{array}{l}\text { TMLR, } \\
\% / \mathrm{min} .\end{array}$ & $\begin{array}{l}W A, \\
\%\end{array}$ & $M D T,{ }^{\circ} \mathrm{C}$ & $\begin{array}{l}\text { TMLR, } \\
\% / \min .\end{array}$ & $\begin{array}{l}W A, \\
\%\end{array}$ & $M D T,{ }^{\circ} \mathrm{C}$ & $\begin{array}{l}T M L R, \\
\% / \min .\end{array}$ \\
\hline EPDM & 0.0 & 472 & 35.7 & 0.0 & 470 & 34.1 & 2.8 & 437 & 2.6 \\
\hline FEPM & 3.6 & 504 & 55.7 & 6.4 & 506 & 53.9 & 0.0 & 488 & 52.0 \\
\hline FFKM-A & $* * * *$ & $* * * *$ & $* * * *$ & $* * * *$ & $* * * *$ & $* * * *$ & 0.0 & 544 & 77.4 \\
\hline FFKM-B & 12.5 & 477 & 62.0 & 13.8 & 466 & 61.1 & 0.0 & 469 & 57.1 \\
\hline FFKM-C & 0.0 & 472 & 82.4 & 0.0 & 475 & 81.9 & 0.0 & 480 & 77.2 \\
\hline
\end{tabular}

$* * * *$ No experimental work was undertaken.

\section{Conclusions}

The mineral additive-free FFKM nanocomposite was prepared by blending FFKM as matrix and highly crosslinked nano-sized fluoropolymer particles fabricated by using the advanced branching and pseudo-living polymerization technology of the fluorinated diene, $\mathrm{CH}_{2}=\mathrm{CH}\left(\mathrm{CF}_{2}\right)_{6} \mathrm{CH}=\mathrm{CH}_{2}$. To evaluate the performance of this elastomeric FFKM nanocomposite in mitigating silica- and silicate-scaling, minimizing the rate of thermochemicaland heat-initiated oxidations, and maintaining mechanical behaviors at a high temperature, the O-rings made with this nanocomposite were exposed in five different simulated geothermal environments at $300^{\circ} \mathrm{C}: 1$ ) sodium metasilicate (SMS)-dissolved steam ( $\mathrm{pH}$ 11.8)-cooling cycle in $\mathrm{N}_{2}$ and 2) in air, 3) Ca-bentonite clay (aluminum phyllosilicate)-based drilling fluid (pH 9-10), 4) $\mathrm{CO}_{2}$-rich geo-brine fluid ( $\mathrm{pH} 4-5$ ), and 5) thermal-shock cycles. All thermochemical-exposure tests including the environments 1 to 4 were carried out under a pressure of 8.3 MPs. For comparison, four other O-rings were made with EPDM, FEPM, and two different FFKMs composites containing mineral additives. For the FFKMs, they were assembled by conventional branching and pseudo-living polymerization to create additional cross-links in the polymer structure, so that this polymer structure was characterized as ethylene (E)-crosslinked- 
poly[tetrafluoroethylene (TFE)-co-perfluoromethylvinylether (PMVE)]. Compared with this, the content of PMVE in FFKM nanocomposite system was lower than that of these mineral-filled FFKM composites.

The following conclusions can be drawn from the results from post-test analyses for each O-ring material. For all O-rings, there were four major factors promoting their degradation caused by $300^{\circ} \mathrm{C}$ thermochemical and thermal shock environments:1) The susceptibility of $-\mathrm{CH}_{2}$ hydrocarbon groups to oxidation reactions; 2) the incorporation of oxidation derivatives, such as $\mathrm{C}=\mathrm{C}, \mathrm{C}=\mathrm{O}$, and $\mathrm{COO}^{-}$groups, into the polymer; 3) the sensitivity of mineral additive to the reaction with $\mathrm{CO}_{2}$ (gas); and, 4) water uptake by mineral additives or degraded polymers, or both. These factors were directly correlated with the magnitude of irremovable silica- and silicatescaling, the changes in tensile strength and ultimate elongation, and the disintegration of the Orings.

The factors 1 and 2, particularly in geo-brine fluid, led to a considerable scaling. The high rate of scale deposition played pivotal rules in changing the mechanical behaviors of the O-rings; namely, the elastic properties of O-rings were enhanced as means of their degradation. Such degradation engendered an extended softening of O-rings, corresponding to their reduced tensile strength and the increased ultimate elongation. In fact, FFKM-B possessing the highest susceptibility of the $-\mathrm{CH}_{2-}$ group to oxidation reactions had the most extensive coverage of scaling over the O-rings; in contrast, the EPDM, FEPM, and FFKM-C along with their relatively lower susceptibility disclosed a minimum coverage. Furthermore, the SMS steam-cooling cycle tests in $\mathrm{N}_{2}$ and air strongly verified that the magnitude of scaling depended on the extent of oxidation; in fact, aerated steam resulted in more scale precipitation on the O-ring's surface compared with that in $\mathrm{N}_{2}$. On the other hand, the susceptibility of $-\mathrm{CH}_{2}$ - in Ca-bentonite clay (aluminum phyllosilicate)-based drilling fluid was less than that in all other thermochemical environments, reflecting a moderate silicate fouling. Thus, this fact suggested that the drilling fluid containing organic chemicals preferentially reacted with any other chemical groups in Orings to promote their degradation, rather than with the $-\mathrm{CH}_{2}$ - groups.

Factor 3 was especially related to the specific oxide-based mineral additive, like $\mathrm{K}_{2} \mathrm{O}$, which was vulnerable to carbonation in thermal shock environment. Correspondingly, the $\mathrm{K}_{2} \mathrm{O}$-related additive-filled FFKM-B was detrimental to this environment; namely, the disintegration of this O-ring was dependent on the in-situ transformation of the $\mathrm{K}_{2} \mathrm{O}$ additive into water-soluble $\mathrm{K}$ carbonate, but not was independent of oxidation of FFKM itself. Also, the water uptake of this O-ring due to adding $\mathrm{K}_{2} \mathrm{O}$ occurred in all thermochemical environments relevant to factor 4 . The water uptake by the combination of the oxidative degradation of the polymers and the presence of mineral additives was observed from the FEPM and FFKM-A O-rings containing $\mathrm{CaO}$ - and $\mathrm{ZnO}$-rich minerals. Assuming that such oxidative degradation and water absorption generates structural defects in the O-rings, one concern was the undesirable alteration of smooth 
O-ring surface texture to a rough one, which may attract the scale to adhere mechanically to rough O-ring's surfaces. Only one O-ring made with FFKM nanocomposite did not determine water absorption during all thermochemical and thermal shock environments. Regarding the mineral-filled EPDM composite, although there were no signs of any water uptake by this O-ring in all thermochemical environments, it was degraded by thermal shock, allowing water to permeate through it. Thus, it appeared that water uptake by O-rings was one critical issue to be addressed for evaluating their integrity because of the loss of their effectiveness in sealing.

In the thermal shock environment, unlike the thermochemical environments, the combined activity of dry carbonation and heat oxidation undermined the integrity of EPDM and FFKM-B O-rings. On the other hand, the results from the susceptibility measurements of $-\mathrm{CH}_{2}$ - groups demonstrated that the ranking of thermal shock stability of polymer alone without mineral additives was in order; FFKM-A >FFKM-B > FFKM-C > FEPM >EPDM.

Nevertheless, the integration of all information strongly demonstrated that mineral additive-free FFKM-C nanocomposite displayed the best performance in maintaining the integrity of O-ring in these five different environments and also possessed an excellent compatibility with these environments, compared with that of all mineral additive-filled O-rings. Additionally, the tensile strength and ultimate elongation of this nanocomposite O-ring was equal to and even better compared with that of mineral additive-filled composite O-rings. Thus, it has a high potential not only for use as O-rings, but also as other components of drilling tools, such as gaskets, seals, and packers.

\section{Recommendation}

Based upon all the BNL-SNL collaborative works over the past two years to identify advanced high temperature-stable elastomeric materials and their composites that remain unchanged and withstand in various different harsh geothermal environments at $300^{\circ} \mathrm{C}$, including aerated and non-aerated silica-laden steams, water-based drilling fluid, $\mathrm{CO}_{2}$-rich geo-brine as well as heatwater quenching, we can recommend three elastomeric materials to use in conducting future field-validation tests at the Omat power plant sites. This will ensure that these materials satisfactorily maintain their integrity and reliability in a real geo-thermochemical environment. Among the selected materials are high-temperature steam-resistant EPDM, FEPM, and FFKM. These materials will be reinforced with proper mineral-and organic-based additives to fabricate conventional composite- and upgraded nanocomposite-structures. The fabricated end-products for field tests will be O-rings, packers, and non-metallic water-lubricant pump bearings.

\section{Acknowledgement}

O-ring samples made by E. I. du Pont de Nemours and Company were supplied by Erica Redline (SNL) as part of our collaboration efforts between BNL and SNL. Research also was carried out in part at the Center for Functional Nanomaterials, Brookhaven National Laboratory, which is supported by the US Department of Energy, Office of Basic Energy Sciences, under Contract No. DE-SC0012704. 


\section{References}

1. J. Walters, S. Thorhallsson, and E. Wood, International partnership for geothermal technology zonal isolation for geothermal wells, Working Group Documents, August, 2012.

2. C.W. Klein, Management of fluid injection in geothermal wells to avoid silica scaling at low levels of silica oversaturation, Geothermal Resources Council Transactions, 19 (1995) 503-511.

3. V.N. Kashpura and V.V. Potapov, Study of the amorphous silica scales formation at the mutnovskoe hydrothermal field (Russia), Proceedings, Twenty-Fifth Workshop on Geothermal Reservoir Engineering Sanford University, Stanford, California, January 2426, 2000 SGP-TR-165.

4. V.A. Grobach, V.V. Potapov, V.N. Kashpura, N.A. Tyurina, and S.V. Zubaha, Silicic acid polymerization in hydrothermal solution, Proceedings, Twenty-Fifth Workshop on Geothermal Reservoir Engineering Sanford University, Stanford, California, January 30February 1, 2006 SGP-TR-179.

5. M. Haklidir and F.T. Haklidir, Fuzzy control of calcium carbonate and silica scales in geothermal systems. Proceedings World Geothermal Congress 2015 Melbourne, Australia, 19-25 April 2015.

6. T. Sugama, T. Pyatina, E. Redline, J. McElhanon, and D. Blankenship, Degradation of different elastomeric polymers in simulated geothermal environments at $300^{\circ} \mathrm{C}$, Polymer Degradation and Stability 120 (2015) 328-339.

7. G. Conino, S. Danese, S. Arrigoni, M. Albano, and M. Apostolo, New pefluoroelastomers for semi-conductor application, Proceedings, High Performance Elastomer 2000 Conference, October 10-11, Crowne Plaza, Berlin, Germany, pp 122123.

8. A. Vicenzo and A. Marco, Branching and pseudo-living technology in the synthesis of high performance fluoroelastomers, Rubber World 224 (2001) 27.

9. M. Apostolo and F. Triulzi, Properties of fluoroelastomer/semicrystalline perfluoropolymer nano-blends, Journal of Fluorine Chemistry 125 (2004) 303-314.

10. Y. Bao, J. Ma, and Li Na, Synthesis and swelling behaviors of sodium carboxymethyl cellulose-g-poly(AA-co-AM-co-AMPS)/MMT superabsorbent hydrogel, Carbohydrate Polymers 84 (2011) 76-82.

11. S. Mishar, GU. Rani, and G. Sen, Microwave initiated synthesis and application of polyacrylic acid grafted carboxymethyl cellulose, Carbohydrate Polymers 87 (2012) 2255-2262.

12. T. Sugama, T. Pyatina, and A. Muraca, Role of PVA flakes in promoting self-degradation of sodium metasilicate-activated cement under a hydrothermal environment at $\geq 150^{\circ} \mathrm{C}, \mathrm{J}$. Technology Innovations in Renewable Energy 2 (2013) 352-365. 
13. Q. Zhao, X. Li, and J. Gao, Surface degradation of ethylene-propylene-diene monomer (EPDM) containing 5-ethylidene-2-norbornene (ENB) as diene in artificial weathering environment, Polymer Degradation and Stability 93 (2008) 692-699.

14. G. Tang, Y. Hu, and L. Song, Study on the flammability and thermal degradation of a novel intumescent flame retardant EPDM composite, Procedia Engineering 62 (2013) 371-376.

15. T. Nakamura, O. Chaikumpollert, Y. Yamamoto, Y. Ohtake, and S. Kawahara, Degradation of EPDM seal used for water supplying system, Polymer Degradation and Stability 96 (2011) 1236-1241.

16. A. Fidalgo and L.M. Ilharco, The defect structure of sol-gel-derived silica/polytetrahydrofuran hydride films by FTIR, Journal of Non-Crystalline Solids 283 (2001) 144-154.

17. P. Innocenzi, P. Falcaro, D. Grosso, and F. Babonneau, Order-disorder transition and evolution of silica structure in self-assembled mesostructured silica films studied through FTIR spectroscopy, Journal of Physical Chemistry 107 (2003) 4711-4717.

18. V. Ramasamy and G. Suresh, Mineral characterization and crystalline nature of quartz in Ponnaiyar river sediments, tamilnadu, India, American-Eurasian Journal of Science Research 4 (2009) 103-107.

19. S.J. Lim, K.K. Gleason, D.J. Edell, and E.F. Gleason, Flexible fluorocarbon wire coatings by pulsed plasma enhanced chemical vapor deposition, Journal Vacuum Science Technology A 15 (1997) 1814-1818.

20. A. Gruger, A. Regis, T. Schmatko, and P. Colomban, Nanostructure of Nafion ${ }^{\circledR}$ membranes at different states of hydration An IR and Raman study, Vibrational Spectroscopy 26 (2001) 215-225.

21. S. Mitra, A. Ghanbari-Siahkalia, P. Kingshotta, K. Almdala, H.K. Rehmeierb, and A. G. Christensenc, Chemical degradation of fluoroelastomer in an alkaline environment, Polymer Degradation and Stability 83 (2004) 195-206.

22. C. Biloiu, I. A. Biloiu, Y. Sakai, Y. Suda, and A. Ohta, Amorphous fluorocarbon polymer (a-C:F) films obtained by plasma enhanced chemical vapor deposition from perfluorooctane $\left(\mathrm{C}_{8} \mathrm{~F}_{18}\right)$ vapor I: Deposition, morphology, structure and chemical properties, Journal Vacuum Science Technology A 22 (2004) 13-19.

23. L. Gubler, N. Prost, S.A. Gursel, and G.G. Schere, Proton exchange membranes prepared by radiation grafting of styrene/divinylbenzene onto poly(ethylene-alttetrafluoroethylene) for low temperature fuel cells, Solid State Ionic 176 (2005) 28492860.

24. V. Saarinen, T. Kallio, M. Paronen, P. Tikkanen, E. Rauhala, and K. Kontturi, New ETFE-based membrane for direct methanol fuel cell, Electrochimica Acta 50 (2005) 3453-3460.

25. S. Phongtamrug, K. Tashiro, A. Funaki, K. Arai, and S. Aida, Structure study of a series of ethylene-tetrafluoroethylen copolymers with various ethylene contents, Part I: 
Structure at room temperature investigated for uniaxially-oriented samples by an organized combination of 2D-WAXD/SAXS and IR/Raman spectra, Polymer 49 (2008) 561-569.

26. A.N. Geraldes, H.A. Zen, G. Ribeiro, H.P. Ferreira, C.P. Souza, D.F. Parra, E.I. Santiage, and A.B. Lugao, Post-irradiation time effects on the graft of poly(ethylene-alttetrafluoroethylene) (ETFE) films for ion exchange membrane application, Radiation Physics and Chemistry 79 (2010) 246-249.

27. S. Radice, V. Tortelli, M. Causa, C. Castiglioni, and G. Zerbi, Quantum mechanical calculations and spectroscopic analysis of fluorinated vinyl ether molecules, Journal of Fluorine Chemistry 95 (1999) 105-116.

28. T.W. Baughman, E. ven der Aa, S.E. Lehman, K.B. Wagener, Circumventing the reactivity ration dilemma: Synthesis of ethylene-co-methyl vinyl ether copolymer, Macromolecules 38 (2005) 2550-2551.

29. G. Marchionni, G. Ajroldi, A.M. Staccione, P. Dardani, and G. Pezzin, Synthesis and characterization of perfluoropolyethers from perfluoromethylvinylether. Journal of Fluorine Chemistry 95 (1999) 85-95.

30. A.G. Xyla and P.G. Koutsoukos, Quantitative analysis of calcium carbonate polymorphs by infrared spectroscopy. Journal of Chemical Society, Faraday Trans.1 85 (1989) 31653172.

31. S. Gunasekaran, G. Anbalagan, and S. Pandi, Raman and infrared spectra of carbonate of calcite structure, Journal of Raman spectroscopy 37 (2006) 892-899.

32. N.A. Marley, P. Bennett, D.R. Janecky, and J.S. Gaffney, Spectroscopic evidence for organic diacid complexation with dissolved silica in aqueous systems-I. Oxalic acid, Organic Geochemistry 14 (1989) 525-528.

33. E. Mavredaki, E. Neofotistou, and K.D. Demadis, Inhibition and dissolution as dual mitigation approaches for colloidal silica fouling and deposition in process water systems: Functional synergies, Industrial \& Engineering Chemistry Research 44 (2005) 7019-7026.

34. K.D. Demadis and A. Stathoulopoulou, Solubility enhancement of silicate with polyamine/polyammonium cationic macromolecules: Relevance to silica-laden process waters, Industrial \& Engineering Chemistry Research 45 (2006) 4436-4440.

35. G. Tang, Y. Hu, and L. Song, Study on the flammability and thermal degradation of a novel intumescent flame retardant EPDM composite, Procedia Engineering 62 (2013) 371-376. 